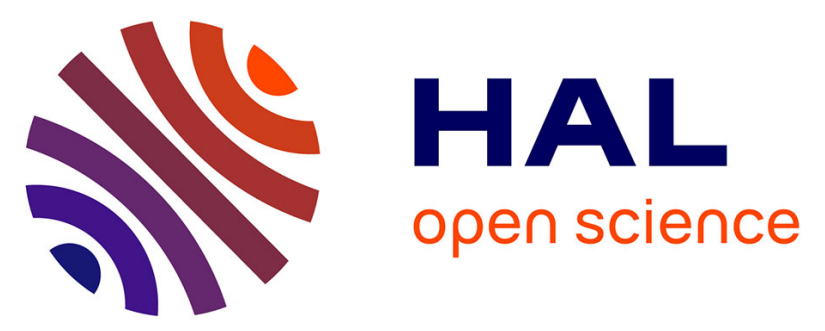

\title{
Do early diagenetic processes affect the applicability of commonly-used organic matter source tracking tools? An assessment through controlled degradation end-member mixing experiments
}

\author{
Morgane Derrien, Heybin Choi, Emilie Jardé, Kyung-Hoon Shin, Jin Hur
}

\section{To cite this version:}

Morgane Derrien, Heybin Choi, Emilie Jardé, Kyung-Hoon Shin, Jin Hur. Do early diagenetic processes affect the applicability of commonly-used organic matter source tracking tools? An assessment through controlled degradation end-member mixing experiments. Water Research, 2020, 173, pp.Art. $\mathrm{n}^{\circ} 115588$. 10.1016/j.watres.2020.115588 . insu- 02475407

\section{HAL Id: insu-02475407 \\ https://hal-insu.archives-ouvertes.fr/insu-02475407}

Submitted on 19 Mar 2020

HAL is a multi-disciplinary open access archive for the deposit and dissemination of scientific research documents, whether they are published or not. The documents may come from teaching and research institutions in France or abroad, or from public or private research centers.
L'archive ouverte pluridisciplinaire HAL, est destinée au dépôt et à la diffusion de documents scientifiques de niveau recherche, publiés ou non, émanant des établissements d'enseignement et de recherche français ou étrangers, des laboratoires publics ou privés. 
$11{ }^{c}$ University of Rennes 1, CNRS, Géosciences Rennes, UMR 6118, Rennes, France

$20 *$ Corresponding author

21 Tel. +82-2-6935-2634

22 E-Mail: morganederrien@sejong.ac.kr; jinhur@sejong.ac.kr 


\section{ABSTRACT}

In the development of organic matter (OM) source tracking tools, it is critical to validate

25 if (1) the tracers are conservative with source mixing, and (2) they can be conservative under

26 diagenetic processes (e.g., microbial degradation). In this study, these two critical points were

27 rigorously tested for three commonly-used source tracking tools (i.e., absorbance and

28 fluorescence proxies, stable carbon isotopes and lipid biomarkers) via a controlled experiment at

29 laboratory scale. To this end, two end-members (e.g., soil and algae), which represent the most

30 common and contrasted sources of OM to sediments in an aquatic environment, were mixed in

31 different ratios and then incubated under different oxygen conditions (oxic versus anoxic) in the

32 dark at $25^{\circ} \mathrm{C}$ for 60 days. The initial and final signals of the source tracking tools were analyzed

33 and compared for each mixing ratio. Based on three evaluation criteria concerning the linearity

34 of the relationships, discrimination sensitivity, and conservative mixing behavior, we evaluated

35 the applicability of the tools to trace the sediment organic matter in the aquatic environment.

36 Although most of the source tracking proxies evaluated in this study showed a conservative

37 nature after incubation, there are only a few that demonstrated both conservative behaviors with

38 the sources mixing and under early diagenetic processes. The fluorescence proxies such as the

39 relative distribution of a humic-like component associated with refractory source material

40 (Ex/Em: 220/430nm), modified fluorescence index (YFI), humification index (HIX), and carbon

41 stable isotope ratios were identified to be the most reliable tracers for tracking sedimentary OM

42 sources under early diagenetic processes. This study provides strong insights into the validation

43 of common OM source tracking tools for sediment and a reasonable guideline to select the

44 optimum indices for source discrimination via end-member mixing analysis. 
46 Keywords: Sources tracking tools; Organic matter; Sediments; Biodegradation; End-member 47 mixing.

\section{INTRODUCTION}

Natural organic matter (NOM) is generated by the breakdown and degradation of

51 organisms involving hydrosphere, biosphere, and geosphere through diverse biological,

52 chemical, and physical processes in the natural environment (Sillanpää, 2015). NOM sources are

53 usually classified as allochthonous or autochthonous. Allochthonous OM, which occurs from

54 outside the aquatic environment, consists of terrigenous materials, such as vascular plants,

55 leaves, root exudates, and soils, exported from the upstream catchment into rivers and lakes. By

56 contrast, autochthonous $\mathrm{OM}$, which is produced within water bodies, derives from aquatic biota

57 (e.g., algae, bacteria, plankton, macrophytes, and nekton) (Derrien et al., 2019a; Volkman and

58 Tanoue, 2002). In aquatic systems, sediments represent a large reservoir of nutrients and NOM

59 from both inputs in various proportions (Briand et al., 2015; Fisher et al., 2005; Southwell et al.,

60 2010; Waterson and Canuel, 2008; Zhang et al., 2009). Indeed, sedimentary OM is derived from

61 bacteria or plankton formed in situ, but also receives allochthonous OM from the upstream

62 catchment. Soil OM is a representative allochthonous OM source and it is easily transported into

63 the rivers and ends up in sediments through hydrological processes (van der Meij et al., 2018).

64 Nowadays, terrestrial organic matter input into surface waters is one of the major concerns in the

65 context of the current climate changes as it is observed in polar regions with the release of

66 “dormant” carbon from permafrost (Bischoff et al., 2016; Vonk et al., 2015; Wild et al., 2019).

67 Sediments are also a reactive compartment where diagenetic processes occur inducing changes.

68 The processes may be physical, chemical, and/or biological in nature and may occur at any time 
69 subsequent to the arrival of a particle at the sediment-water interface (Henrichs, 1992;

70 Kuznetsova et al., 2019; Milliken, 2003). Among the early diagenetic processes, biodegradation

71 plays a key role as it is one of the main processes causing changes in amount, composition and

72 properties of OM in sediment (Arndt et al., 2013; Derrien et al., 2019a; Guenet et al., 2014).

74 a thorough understanding of OM dynamics and its role in the carbon cycle at a local and global

75 scale (Gordon and Goni, 2003; Pedrosa-Pàmies et al., 2015). Identifying, apportioning and

76 tracking the sources of $\mathrm{OM}$ in aquatic systems require robust, reliable and effective source

77 tracking tools. Absorbance and fluorescence proxies, stable carbon isotopes, and lipid

78 biomarkers are the most commonly-used OM source tracking tools in aquatic systems (Aiken,

79 2014; Bianchi and Canuel, 2011; Derrien et al., 2017; Meyers, 1994). These tools have been

80 applied in diverse environments including soils, sediments, pore-water, river, lakes, and oceans

81 for several decades (Amiotte-Suchet et al., 2007; Benner et al., 1997; Derrien et al., 2015; Fichot

82 et al., 2013; Jaffé et al., 2004; Meyers and Ishiwatari, 1993; Toming et al., 2013; Wakeham and

83 Canuel, 1990; Zimmerman and Canuel, 2001; Zsolnay et al., 1999). Although these tools have

84 been used for decades, their applicability and potential limitations have not been rigorously

85 examined yet. Nevertheless, to fully validate their use, two critical points need to be examined:

86 1) conservative behavior with sources mixing, and 2) conservative behavior under early

87 diagenetic processes (e.g., microbial degradation). In our previous study, based on a simple

88 mixing POM end-member experiment, we demonstrated that the conservative behavior of the

89 OM source tracking tools with the mixing source is not obvious and finally raised the question of

90 the reliability of some of the most commonly-used tools (Derrien et al., 2019b). More recently,

91 we also investigated the biodegradation-induced changes in the porewater DOM for different 
92 sources (Derrien et al., 2019c). The results of the latter study suggested the existence of different

93 pathways of biodegradation with both positive and negative priming effects depending on the

94 sources and the ratio of labile material. All these observations clearly justify the questioning of

95 the applicability to these tools in natural systems and the necessity to test them for both criteria.

96 In this context, we designed a controlled degradation experiment at laboratory scale using

97 organic-rich sediments artificially composed of two contrasting OM end-members (i.e., soil and

98 algae) at known mixing ratios. The incubations were performed under oxic and anoxic conditions

99 in order to reproduce different configurations of natural sediment (Kristensen, 2000). Hence, this

100 study aimed to establish the applicability of 3 commonly-used source tracking tools (i.e.,

101 absorbance and fluorescence proxies, stable carbon isotopes, and lipid biomarkers) during early

102 diagenetic processes in the natural environment. As a result, the specific objectives of this study

103 were (i) to study the influence of oxygen on the degradation-induced changes, and (ii) to

104 examine the conservative/non conservative behaviors of the three source discrimination tools in

105 artificial sediments before and after biodegradation, and (iii) to evaluate the conservative/non

106 conservative behaviors of the three source discrimination tools with sources mixing in the

107 artificial sediments.

108

109 2. MATERIAL AND METHODS

110 2.1. Experimental design of the incubation experiment

111 Two end-members (i.e., soil and algae), as the major organic sources of sediments, were

112 mixed at soil to algae ratios of 100:0, 75:25, 50:50, 25:75, and 0:100, respectively, on the basis

113 of organic carbon (OC) concentrations, not their masses, after the OC contents of the two end-

114 members were taken into account. Briefly, a topsoil $(0-10 \mathrm{~cm})$ sample was collected as the soil 
115 end-member at Bukhansan National Park (3743’37.0” N 12700’50.9”) in South Korea. A 116 commercial unicellular green alga (Chlorella vulgaris), which is commonly found in lakes and

117 ponds in South Korea, was purchased as the algae end-member from Aquanet Co., Ltd. in 118 Gyeongsangnam-do, South Korea. Detailed information on the two end-members can be found 119 in Derrien et al., 2019b.

120 Incubation experiments in oxic and anoxic conditions were performed in pre-washed and 121 pre-combusted $\left(450^{\circ} \mathrm{C}\right.$ for 4 hours $) 125 \mathrm{ml}$ Wheaton ${ }^{\circledR}$ amber glass bottles with Teflon 122 screwcaps. Samples for anoxic incubation were prepared and sampled using sterile Aldrich ${ }^{\circledR}$ 123 AtmosBag two-hand glove bag. A mass (12 g) of the end-member mixture samples were mixed 124 with ultrapure water (Barnstead ${ }^{\mathrm{TM}}$ Easypure $^{\mathrm{TM}}$ RoDi, Thermo Scientific) at a solid to solution 125 ratio of 1:4 and equilibrated for $48 \mathrm{~h}$ in the dark at room temperature after shaking at $100 \mathrm{rpm}$ for 126 one hour. River water from Jungnang river in Seoul $\left(37^{\circ} 40^{\prime} 16^{\prime \prime} \mathrm{N}, 127^{\circ} 04^{\prime} 47^{\prime \prime} \mathrm{E}\right)$ was used as 127 inoculum for microbial incubation. The collected river water sample was first passed through a 128 GF/C (pre-combusted, $1.2 \mu \mathrm{m}$ pore-sized) and $10 \mathrm{mM}$ of inorganic nutrients $\left(\mathrm{NH}_{4} \mathrm{NO}_{3}\right.$ and $129 \mathrm{~K}_{2} \mathrm{HPO}_{4}$ ) was added to the filtered river water for sufficient microbial growth. Then, the 130 inoculum solution was covered by aluminum foil to protect the solution from light to avoid the 131 growth of algae and finally kept at room temperature under slow shaking (80 rpm) for 2 days. 132 Prior to incubation, all artificial sediment samples were spiked with $3 \%(\mathrm{v} / \mathrm{v})$ of the prepared 133 inoculum, and a sufficient amount $(1 \%, \mathrm{v} / \mathrm{v})$ of nutrients $\left(\mathrm{NH}_{4} \mathrm{NO}_{3}\right.$ and $\mathrm{K}_{2} \mathrm{HPO}_{4}$ at $\left.10 \mathrm{mM}\right)$ was 134 added to each sample to avoid nutrient limitations during the incubation. Finally, the samples in 135 oxic and anoxic conditions were incubated in the dark at $25^{\circ} \mathrm{C}$ for 60 days (Guenet et al., 2014; 136 Navel et al., 2012). No control was prepared because it required the poisoning of the samples 137 with either mercuric chloride or sodium azide, which are extremely toxic and environmentally 
138 harmful and more importantly result in fluorescence quenching (Park and Snyder, 2018;

139 Retelletti Brogi et al., 2019). Samples under oxic conditions were aerated every 3 days under a

140 fume hood in order to minimize the contamination by microorganisms in the air. Samples were

141 sacrificed for sampling on day 0 and day 60, with "day 0" corresponding to the day when the

142 samples were inoculated. The degradation experiments were carried out in duplicate.

143 The sampling was performed according to the following. First, samples were taken from the

144 incubator and the overlying water was carefully removed not to disturb the sediment. The

145 artificial sediment samples were then centrifuged at $5000 \mathrm{rpm}$ for $20 \mathrm{~min}$ to remove the 146 porewater. Finally, the porewater-free sediment samples were freeze-dried, ground, and

147 homogenized for further analyses.

148

149

\subsection{Spectroscopic measurements}

150 To investigate the absorbance and fluorescence properties of the artificial sediment, it is 151 necessary to perform an extraction of the OM (e.g., extraction of the dissolved OM from the 152 sedimentary OM). Extraction can be performed with different solvents. According to our 153 previous results comparing common solvent-based OM extraction methods, the water extraction 154 was identified as the preferred extraction method for the application of the spectroscopic tool to 155 POM source discrimination (Derrien et al., 2019b). In this study, the same procedure was used to 156 obtain the water-extractable organic matter (WEOM) of the artificial sediment samples.

157 The dissolved organic carbon (DOC) concentrations were measured using a Shimadzu V-

158 CPH TOC analyzer. The absorption spectra were scanned from 200 to $800 \mathrm{~nm}$ at $0.5 \mathrm{~nm}$-interval 159 using an ultraviolet-visible (UV-vis) spectrometer (Shimadzu UV-1300). The fluorescence 160 excitation-emission matrices (EEMs) were obtained with a luminescence spectrometer (Hitachi 
161 F7000, Japan) following the procedure previously described by Retelletti Brogi et al. (2019). A

162 total of 82 EEMs were collected for the PARAFAC modeling, and it was processed using

163 MATLAB R2013b (Mathworks, USA) with the drEEM toolbox (Murphy et al., 2013). The

164 validation of the PARAFAC model was made by split-half analysis and percentage of explained

165 variance (>99.5\%). By using corrected EEMs, several classical fluorescence indices (e.g.,

166 fluorescence index and modified fluorescence index: FI and YFI, the humification index: HIX,

167 and the index of recent autochthonous contribution BIX) were calculated (Heo et al., 2016;

168 Huguet et al., 2009; Zsolnay et al., 1999). The maximum fluorescence intensities $\left(\mathrm{F}_{\max }\right)$ of the

169 identified PARAFAC components were used to represent their relative abundance (\%).

171 2.3. Carbon and nitrogen stable isotope ratio analyses

172 Before carbon stable isotope analysis, inorganic carbon was removed by $1 \mathrm{~N} \mathrm{HCl}$

173 treatment, whereas untreated samples were directly used for the nitrogen isotope ratio analysis

174 (Carabel et al., 2006). The total organic carbon (TOC) and the carbon stable isotope ratio $\left(\delta^{13} \mathrm{C}\right)$

175 were measured using an elemental analyzer that was coupled with an isotope ratio mass

176 spectrometer (EA-IRMS; EuroEA-Isoprime IRMS, GV Instruments, UK). Stable isotope ratios

177 were calculated using the standard d notation:

$$
\delta^{13} C(\% 0)=\left(\left(R_{\text {sample }} / R_{\text {Reference }}\right)-1\right) \times 1000
$$

178 where $\mathrm{R}$ is the corresponding ratio of ${ }^{13} \mathrm{C} /{ }^{12} \mathrm{C}$. The standard reference material was IAEA-CH-3, 179 Cellulose ( $\delta^{13} C=-24.724 \pm 0.041$ (vs VPDB, Vienna Pee Dee Belemnite)). The analytical 180 precision was $0.05 \%$. 
The total lipid fraction of the artificial sediments was extracted with dichloromethane 184 using an accelerated solvent extractor (ASE 200, Dionex). Conditions of the extraction are

185 described in Derrien et al. (2011). The total lipid extract was then fractionated using solid/liquid 186 chromatography (silica column) to isolate the polar fraction. The polar fraction was derivatized 187 with a mixture of N,O-bis-(trimethylsilyl)trifluoroacetamide and trimethylchloro-silane (BSTFA $188+$ TMCS, 99/1, v/v, Supelco) after addition of $5 \alpha$-cholestane (CDN isotope) as an internal 189 standard (IS). Derivatized samples were analyzed by gas chromatography-mass spectrometry 190 (GC-MS) using a Shimadzu QP2010plus equipped with a capillary column (Supelco, $19160 \mathrm{~m} \times 0.25 \mathrm{~mm}$ ID, $0.25 \mu \mathrm{m}$ film thickness). The temperature of the transfer line was set at $280^{\circ} \mathrm{C}$, 192 and molecules were ionized by electron impact using the energy of $70 \mathrm{eV}$. The temperature of 193 the ionization source was set at $200^{\circ} \mathrm{C}$. Samples were injected in splitless mode at $310^{\circ} \mathrm{C}$. The 194 oven temperature was programmed from an initial temperature of $200^{\circ} \mathrm{C}$ (held for 1 min) then 195 rising to $310^{\circ} \mathrm{C}$ at $15^{\circ} \mathrm{C} / \mathrm{min}$ (held for $35 \mathrm{~min}$ ). Helium was used as the carrier gas, with a flow 196 rate of $1.0 \mathrm{~mL} / \mathrm{min}$. The analyses were made in selective ion monitoring mode (SIM). The 197 compound identification was performed based on the comparison of the retention times and the 198 mass spectra with the available standards or the literature data (Table S1) (Debieu et al., 1992;

199 Derrien et al., 2019b; Harrault et al., 2019). The quantification was achieved with a 5-point 200 internal calibration curve (two series of calibration solutions: $0.1,0.3,0.5,0.7$ and 1ppm or 1, 3, 2015 , 7, and $10 \mathrm{ppm}$ ) of sterol and stanol standards with a constant IS concentration at 0.5 or 5 ppm, 202 respectively.

203

\section{2.6. Conservative mixing relationship and statistical analyses}


In order to assess the applicability of the different source tracking tools during early 206 diagenetic processes, several evaluation criteria were established, which were already presented 207 and used in a previous study (Derrien et al., 2019b). First, the linearity of the measured 208 parameters in artificial sediments was examined with respect to the increasing abundance of one 209 end-member (e.g., soil or algae). The relationship was considered "linear" for a high coefficient 210 of determination $\mathrm{R}^{2}>0.8$ and an associated $\mathrm{p}$-value $<0.01$. Then, the regression slope of the 211 measured values (Sm) normalized by the standard deviation of the measurement (Sm/SD) was

212 used to evaluate the sensitivity of the source discrimination. A value of the $\operatorname{Sm} / \mathrm{SD} \geq 0.5$ was 213 considered as an acceptable range for the sensitivity regarding the source discrimination relative 214 to the measurement uncertainty. Finally, the deviation from the ideal values for a conservative 215 mixing relationship was estimated in calculating the percent difference (\%difference) between 216 the slopes for the measured (Sm) and the predicted (Sp) values. The predicted values were 217 calculated using the pure end member's values and the mixing ratios under a linear conservative 218 mixing assumption (Table S2). A \%difference of $<10 \%$ was considered to be an acceptable 219 degree of the deviation for the conservative mixing relationship.

\section{3.RESULTS AND DISCUSSION}

\section{3.1. Spectroscopic indices}

223 3.1.1. Identification of different fluorescent components via EEM-PARAFAC

Four different components were identified, which included two humic-like components

225 (C1 and C2) and two protein-like components (C3 and C4) (Fig. S1). All the identified 226 components were consistent with those previously reported and/or matched well with the Open 227 Fluor database with similarity scores > 0.95 (Table S3). Component 1 (C1), which had a 
maximum at 220/430 nm (Ex/Em), can be assigned to a typical terrestrial humic-like component

229 (Graeber et al., 2012; Retelletti Brogi et al., 2019b; Yamashita et al., 2010). Component 2 (C2),

230 which exhibited the maxima at 220/547 $\mathrm{nm}(\mathrm{Ex} / \mathrm{Em})$ can be associated with a humic-like

231 component or aromatic conjugated macromolecular substances of terrestrial origin (Galletti et

232 al., 2019; Osburn et al., 2016b; Wünsch et al., 2017). Component 3 (C3, peaked at 220,265/361

$233 \mathrm{~nm}(\mathrm{Ex} / \mathrm{Em}))$ and component $4(\mathrm{C} 4$, peaked at 220/309 nm (Ex/Em)) were reported as protein-

234 like substances, namely tryptophan-like and tyrosine-like components, respectively (Cawley et

235 al., 2012; D’Andrilli et al., 2017; Derrien et al., 2019c; Yamashita et al., 2013).

236

237 3.1.2. Changes in the absorbance and fluorescence proxies of the end-members after incubation

238 The original (at 0-day of incubation) spectroscopic characteristics of the end-members for

239 this study were consistent with those reported in our previous study (Derrien et al., 2019b)

240 (Table 1). Briefly, the soil end-member was mainly characterized by a high abundance of both

241 humic-like components, C1 and C2, with the percentages of $>47 \%$ and $>34 \%$, respectively. On

242 the contrary, the algae end-member consisted only of the two protein-like components, C3 and

$243 \mathrm{C} 4$, in equal proportions. Higher values of $\mathrm{SUVA}_{254}\left(>2 \mathrm{~L} \mathrm{mg}^{-1} \cdot \mathrm{m}^{-1}\right)$ and HIX $(>15)$ were

244 observed for the soil end-member corroborating the high content of humic substances (Derrien

245 et al., 2017; Zsolnay et al., 1999) while higher values of YFI (>3.5) and BIX (>1) were for the

246 algae end-member reflecting its allochthonous origin (Heo et al., 2016; Huguet et al., 2009).

247 The biodegradation led to changes in most of the spectroscopic parameters for both end-

248 members (Table 1). Although there were some differences between the two oxygen conditions,

249 these differences were not statistically significant as the p-values were $>0.95$ (e.g., 0.95 and 0.99

250 for soil and algae end-members, respectively). After 60 days of incubation, the soil end member 
251 exhibited a partial $(\sim 30 \%)$ to complete decrease in the abundance for both protein-like 252 components (C3 and C4). For the main fluorescent components, biodegradation induced a slight 253 depletion of the component $\mathrm{C} 1(<10 \%)$ while the second humic-like component (C2) became 254 more enriched by 20 to $30 \%$. Regarding the spectroscopic indices, substantial changes were 255 mainly observed for HIX with an increase of the value from $16.9 \pm 0.7$ to $21.3 \pm 0.2$ under oxic 256 conditions. However, the increase was slight under anoxic conditions. These results suggest the 257 initial consumption of labile substances as reflected by the partial to complete consumption of 258 the two protein-like components, and a production of high molecular weight and aromatic 259 substances (C2) through the alteration of existing compounds (C1) and/or the production of new 260 compounds by autotrophic organisms (Derrien et al., 2019a; Hansen et al., 2016; Kinsey et al., 261 2018).

262 The algae end member also displayed biodegradation-induced changes in the spectroscopic 263 parameters. The most notable change was the decrease in the relative abundance of the C3 264 component (i.e., \%C3) changing from $46.0 \pm 0.8$ to $42.4 \pm 1.1 \%$ in parallel to the increase of the $265 \%$ C4 values from $52.5 \pm 0.6$ to $56.5 \pm 1.1 \%$. The two fluorescence indices, FI and YFI, showed 266 an increasing trend over incubation, with highest increasing trend for FI under oxic conditions 267 (0.7 \pm 0.0 to $1.0 \pm 0.0$ ) and YFI under anoxic conditions (3.6 \pm 0.0 to $4.1 \pm 0.0$ ). The rest of the 268 indices exhibited little to slight changes in the values specifically under anoxic conditions. For 269 instance, BIX presented an increase of $~ 20 \%$ after incubation under anoxic conditions compared 270 to $3 \%$ under oxic conditions. Although the results could be apparently interpreted as the 271 occurrence of a potential effect of the oxygen condition, the t-test demonstrated that these 272 changes were not significant enough (p-values $>0.95$ ). These observations suggest that the 
273 biodegradation-induced changes in the spectroscopic source indices were less pronounced for the

274 algae end-member than for the soil counterpart.

275

276 3.1.3. Biodegradation-induced deviations from a relationships

Biodegradation-induced changes in the absorbance and fluorescence proxies with the

278 increasing of the algal content in the artificial sediments are shown in Figs. 1 and 2. The oxygen

279 condition does not seem to be a critical factor for the biodegradation-induced changes as the

280 results were similar between the oxic and anoxic conditions (p-value of $>0.96$ ). The trends of the

281 proxies at 0 day and 60 days of incubation (i.e., \%C1, \%C2, YFI, HIX, and BIX; Fig. 1 and Fig.

282 2c, d, e) with increasing algal content in the mixture mostly remained the same (p-values $>0.6$

283 for each proxy), which demonstrates a minor effect of the degradation on the changing trends of

284 the signals with source mixing. By contrast, deviations between both incubation times were

285 observed for the proxies including \%C3, \%C4, SUVA 254 , and FI. SUVA 254 and FI (Fig 1 and Fig

286 2a, b) displayed a deviation after biodegradation along with the increase of the algae fraction

287 except for the mixing ratio soil/algae 25/75. However, for \%C3 and \%C4, the deviation is the

288 most pronounced at the particular mixing ratio (i.e., 25/75).

In order to evaluate the applicability of spectroscopic indices to identify OM sources

290 during early diagenesis, the initial relationships between the absorbance/fluorescence proxies and

291 the abundance of algal content in the mixture were investigated (Table 2) and then compared to 292 the relationship after the biodegradation (Table 3). At 0-day of incubation (Table 2), only \%C1, $293 \% \mathrm{C} 2, \% \mathrm{C}$, and $\mathrm{SUVA}_{254}$ satisfied the threshold values of the three evaluation criteria (i.e., $\mathrm{R}^{2}$ 294 with p-value $<0.01, \mathrm{Sm} / \mathrm{SD}>0.5$, and \% difference $>10 \%$ ) for one (e.g. \%C2 and $\mathrm{SUVA}_{254}$ ) or 295 both of the oxygen conditions (e.g. \%C1 and \%C4). The parameters of YFI and HIX can also be 
296 suggested as good indices in terms of the relationship linearity as they meet 2 out of the 3 criteria

297 without any effect of the oxygen condition, while \%C3 and FI seem to be reliable indices for

298 anoxic and oxic conditions, respectively. BIX does not validate any of the criteria. Among these

299 spectroscopic indices, after incubation, only \%C1, YFI and HIX still satisfied all the evaluation

300 criteria for both oxygen conditions after biodegradation except HIX under anoxic condition

301 which did not validate the sensitivity criterion $\left(\mathrm{S}_{\mathrm{m}} / \mathrm{SD}=0.169\right)$ (Table 3$)$. The other indices

302 failed to meet the criteria in terms of linearity, sensitivity and exhibited a higher degree of the

303 deviation from the ideal end-member mixing ratios (i.e., \%C3, \%C4, SUVA $254, \mathrm{FI}$ ) after

304 microbial degradation. The non-conservative behavior of the latter indices is probably related to

305 the labile characteristic of these compounds (protein-like). From the comparison of all

306 spectroscopic proxies using the evaluation criteria at 0-day and 60-days incubation, it can be

307 concluded that the relative abundance of $\mathrm{C} 1$ and the two fluorescence indices, YFI and HIX,

308 represent the optimum fluorescence proxies for the OM source discrimination with varying end-

309 member mixing ratios.

\section{3.2. Carbon isotope ratios}

312 3.2.1. Changes for carbon isotope ratios of the end-members after incubation

313 As has been found for the spectroscopic characteristics, the isotope results of the end-

314 members at 0-day of incubation were similar to those reported in our previous study (Derrien et 315 al., 2019b) and in lines with other literature (Pardue et al., 1976; Yu et al., 2015). The values for 316 the soil end-member were $-27.2 \pm 0.1 \%$ (oxic) and $-26.7 \pm 0.1 \%$ (anoxic), while those of the 317 algae end-member were $-11.9 \pm 0.0 \%$ (oxic) and $-11.4 \pm 0.1 \%$ (anoxic). 
After incubation, the values of each end-member remained invariant suggesting no effect

319 of the biodegradation on the carbon isotopic composition. In addition, no significant difference

320 was observed between the two oxygen conditions as the p-values were $>0.3$ and $>0.9$ for soil and

321 algae end-members, respectively. These results confirm the chemical stability of the $\delta^{13} \mathrm{C}$ to trace

322 the sedimentary OM under the early diagenetic processes irrespective of oxygen presence.

324 3.2.2. Biodegradation-induced deviations from end member mixing analysis (EMMA) 325 relationships

326 Biodegradation-induced changes in the $\delta^{13} \mathrm{C}$ values of the artificial sediment mixtures

327 with the increase of the algal content are shown in Fig. 3. The variation of the $\delta^{13} \mathrm{C}$ values

328 exhibited a linear relationship with the increase of the algal end member fraction both before and

329 after biodegradation (Tables 2 and 3). In addition, the trend of the carbon stable isotope with

330 increasing algal content in the mixture mostly remained the same before and after 60-days of

331 incubation, demonstrating the resistance to isotopic alteration of $\delta^{13} \mathrm{C}$ during sedimentary

332 diagenesis. However, a deviation was exceptionally noted for a mixing ratio with an equal

333 proportion of both end-members (soil/algae, 50/50). The decomposition of OM, mediated by a

334 variety of microbial processes, can progressively modify the bulk composition of the organic

335 substrates because different OM fractions do not have the same degradation rate (Lehmann et al.,

336 2002; Meyers, 1994). Such selective losses of certain OM fractions may lead to a diagenetic shift

337 in $\delta^{13} \mathrm{C}$ (Benner et al., 1997; Harvey et al., 1995), leaving irreversible changes in the original

338 signature. This is probably what was observed in this present study for the 50/50 artificial

339 sediment mixture. Although the stable isotopes are widely recognized as a reliable and robust

340 tool to trace sediment OM sources and their linear and conservative behavior in a context of 
341 artificial end-member mixing (Derrien et al., 2019b), their specificity to individual sources might

342 be weakened by early diagenesis of sediments (Bianchi and Canuel, 2011; Xiao and Liu, 2010). Despite this slight deviation, the $\delta^{13} \mathrm{C}$ tool satisfied the three (and 2 for anoxic condition)

344 established criteria (e.g., linearity, sensitivity, and deviation), evidencing its linear conservative

345 mixing behavior after biodegradation, with the $\mathrm{R}^{2}$ values ranging from 0.969 (oxic) and 0.898

346 (anoxic) with the p-values of $\leq 0.01$, \%difference of $<10 \%$ and a sensitivity Sm/SD of 1.431

347 (oxic condition) (Table 3). These results clearly demonstrate the robustness and reliability of the $348 \delta^{13} \mathrm{C}$ tool for source discrimination of the sedimentary OM even after diagenetic processes.

\section{3.3. Sterols/stanols biomarkers}

351 3.3.1. Changes in the sterol/stanols distributions of the end-members after incubation

352 The original (at 0-day of incubation) biomarker distribution of the end-members for this

353 study was consistent with those reported in our previous study (Derrien et al., 2019b). Briefly,

354 the soil end member was characterized by abundant amounts (> 80\%) of terrestrial sterols, such

355 as sitosterol, stigmasterol, and campesterol (Table 1), which agreed with the previous literature

356 (Bouloubassi et al., 1997; Derrien et al., 2011; Volkman, 2005). Fecosterol, a fungi or lichens

357 sterol biomarker (Debieu et al., 1992), sitostanol (i.e., a by-product of sitosterol) and cholesterol,

358 the most ubiquitous sterol (Leeming and Nichols, 1998), contributed $<10 \%$ of the total 359 sterol/stanol distribution. Unlike the soil end-member, the algae was characterized by a high 360 abundance ( $>70 \%$ ) of ergosterol (i.e., a green algae sterol biomarker) and the occurrence of 361 sitosterol and cholesterol, which corresponded to $\sim 18 \%$ and $~ 5 \%$ of the sterol compounds in the 362 distribution, respectively. 
After biodegradation, the distribution in sterols/stanols in the end-members remained the

364 same, suggesting no effect of biodegradation such as it was observed for the carbon isotopic

365 composition. Likewise, no significant difference was observed between the two oxygen 366 conditions with the p-values of $>0.90$ for both end-members. These results confirm the chemical 367 stability of the biomarkers to trace the sedimentary OM sources under 60 days of diagenesis 368 dominated by biodegradation.

\subsubsection{Biodegradation-induced deviations from EMMA relationships}

Biodegradation-induced changes in the distribution of sterol/stanol biomarkers in the

372 artificial sediments with increasing algal content are shown in Fig. 4. In most cases, the oxygen

373 condition does not seem to be a critical factor for the biodegradation-induced changes, which

374 was observed for all the biomarkers ( $\mathrm{p}$-value $>0.99$ ). For all the biomarkers, the observed

375 distribution values at all varying algal content between 0-day and 60-days of incubation were the 376 same based on paired t-test $(\mathrm{p}$-value $>0.5$ ). These observations demonstrate the chemical 377 stability of these lipid biomarkers to biodegradation-induced alterations.

378 Regarding the applicability of the lipid biomarker to identify the source of the 379 sedimentary OM during early diagenesis, none of them satisfy the established evaluation criteria 380 either at 0-day or 60-days of incubation (Table 2 and 3). Surprisingly, the source-specific 381 biomarkers, found only in one of the two end-members (Table 1) such as ergosterol, fecosterol, 382 campesterol, stigmasterol or sitostanol, even did not follow a conservative behavior with sources 383 mixing before biodegradation as the highest $\mathrm{R}^{2}$ were still $<0.8$ with $\mathrm{p}$-values $>0.05$. For 384 example, campesterol, presented a $\mathrm{R}^{2}$ of 0.695 with a p-values of 0.079 and 0.722 (p385 value=0.068) in oxic and anoxic conditions, respectively (Table 2). It is noteworthy that 
biodegradation-induces changes on the sitostanol resulted in improved linearity criterion with the

$387 \mathrm{R}^{2}$ values changing from $0.530(0.163)$ to $0.638(0.105)$ and $0.544(0.155)$ to $0.723(0.068)$ for 0 -

388 day and 60-days of incubation, respectively and specifically the reduction in the deviation under 389 anoxic condition (i.e., $11.8 \%$ to $6.2 \%$ ). This singular behavior can be related to the nature of the 390 by-products of the biomarker showing a higher sensitivity to microbial alterations (Bull et al., 391 2002). On the other hand, the incapability of the sterols and stanols lipid biomarker to reflect a 392 conservative behavior with sources mixing was already suggested by previous studies (Derrien et 393 al., 2019b; Shah et al., 2007). Nevertheless, it is noteworthy to observe the conservative behavior 394 of these lipid biomarkers under early diagenetic processes.

\subsection{Implications for the applicability of the organic matter source tracking tools}

In this study, the discrimination capacities of the commonly used source tracking tools

398 during biodegradation were evaluated and compared using artificial sediments with different

mixing ratios of two contrasting OM sources. Two modes were observed: (i) conservative

400 behavior in terms of both sources mixing and biodegradation and (ii) single conservative

401 behavior in terms of biodegradation only. The results of this study demonstrated the strong

402 capacity and the robustness of the carbon stable isotope ratios to identify and estimate the source

403 contribution in artificial sediment mixtures under diagenesis processes. Several spectroscopic

404 indices, such as the relative distribution of the specific fluorescent components (i.e., C1: typical

405 terrestrial humic-like component), YFI, and HIX also represent a robust source tracking tools

406 that were applicable for source apportionment to the artificial sediment mixtures samples under

407 the influence of biodegradation. Regrettably, the lipid biomarkers failed in source apportionment

408 in the artificial sediment mixtures. However, they demonstrated a resistance to microbial 
409 alterations in time. Regarding the oxygen conditions, this study provides, for the first time, clear

410 evidence of little to slight effect on the efficacy of the 3 tested sources tracking tools in artificial

411 sediment mixtures.

412 All of these tools were widely utilized to track and estimate OM sources in various 413 aquatic environments, including rivers, groundwater, lakes, coastal area and oceans (Affouri and

414 Sahraoui, 2017; Derrien et al., 2018; Li et al., 2015; Ogrinc et al., 2005; Osburn et al., 2016a;

415 Toming et al., 2013; Zhang et al., 2017). They were used with the assumption of a conservative

416 mixing behavior and stability under diagenetic processes without firstly evaluating the potential

417 limited applicability. But this study provides strong evidence that the application of these

418 commonly-used tools for OM source tracking could lead to a disruption of the source assignment

419 to a wrong estimation of OM source contribution in the context of early diagenesis. Aside from

420 demonstrating a certain weakness to a complete failure of some of the commonly-used source

421 tracking tools to identify and estimate OM source contribution, this study also raises the question

422 of temporal scale. 60 days of incubation correspond to a short period of time at the diagenesis

423 scale. Therefore, it is reasonable to presume that in higher temporal scale, the limitations of the

424 tools may increase to reach the point where the source tracking tools will not be sustainable

425 anymore, leading to misinterpretations of the biogeochemical processes and dynamics of the OM

426 in specific environments.

427 Experiments carried out under controlled conditions can help in identifying the effects 428 that certain factors have on OM dynamics and properties by excluding any interferences that 429 might exist in real environments (Derrien et al., 2019a). In the present case, we tried to elucidate 430 the combined effect of multiple factors (i.e., microbial degradation, mixing sources ratios and 431 oxygen condition). Although the results of this study provide significant insights for the 
432 characterization of the $\mathrm{OM}$ and more generally for the biogeosciences field, it is necessary to be

433 aware of some limitations of this kind of approach (i.e., a limited number of OM sources (i.e., 434 soil and algae) and choice of the degradation time). Nevertheless, in this current framework, 435 carbon stable isotope ratios, the relative distribution of refractory material fluorescent 436 component, YFI and HIX indices could be suggested as a reasonable tracer with the most 437 conservative behavior and the highest sensitivity to source discrimination in the period of early 438 diagenesis.

\section{CONCLUSION}

The applicability of three commonly-used source tracking tools (i.e., fluorescence

442 proxies, carbon stable isotope ratios, and lipid biomarkers) was tested on artificial sediments of 443 different mixing ratios of two contrasting OM sources and after biodegradation for both oxygen 444 conditions (i.e., oxic and anoxic). Based on three evaluation criteria concerning the linearity of 445 the relationships, the discrimination sensitivity, and the conservative mixing behavior, the 446 following conclusions can be drawn:

447 - The oxygen condition seems to make a limited contribution to biodegradation-induced $448 \quad$ changes by comparing initial and final tested properties after 60 days of degradation.

449 - Most of the sources tracking proxies evaluated in this study show a conservative behavior with respect to biodegradation. By contrast, only a few demonstrated a linear relationship with the increasing portion of one end-members in the mixtures.

- The fluorescence proxies such as the relative distribution of a humic-like component associated with refractory source material (C1, Ex/Em: 220/430nm), YFI, and HIX indices were found to be reliable proxies for source tracking after biodegradation. 
- Carbon stable isotope ratios exhibited a linear conservative relationship with varying mixing ratios of end members before and after biodegradation, demonstrating its strong capacity for identifying the source's contribution at any time under diagenesis.

- The biomarkers of sterols/stanols did show a conservative nature under biodegradation however they did not present a good linear and conservative behavior with varying mixing ratios of end members.

Although these results clearly demonstrate the sensitivity to early diagenesis processes to most of the commonly used sources tracking tools, further studies need to be performed to rigorously evaluate the effects of the incubation time, temperature, sediment depth to fully validate these results.

\section{Acknowledgments}

This work was supported by the National Research Foundation of Korea (NRF) grants and was funded by the Korean government (MSIP) (No. 2017R1A4A1015393 and 2017R1D1A1B033546).

\section{References}

Affouri, H., Sahraoui, O., 2017. The sedimentary organic matter from a Lake Ichkeul core (far northern Tunisia): Rock-Eval and biomarker approach. J. African Earth Sci. 129, 248-259. https://doi.org/10.1016/j.jafrearsci.2017.01.017

Aiken, G., 2014. Fluorescence and Dissolved Organic Matter, in: Baker, A., Reynolds, D.M., Lead, J., Coble, P.G., Spencer, R.G.M. (Eds.), Aquatic Organic Matter Fluorescence. Cambridge University Press, Cambridge, pp. 35-74. https://doi.org/DOI: 
Amiotte-Suchet, P., Linglois, N., Leveque, J., Andreux, F., 2007. 13C composition of dissolved organic carbon in upland forested catchments of the Morvan Mountains (France): Influence of coniferous and deciduous vegetation. J. Hydrol. 335, 354-363. https://doi.org/http://dx.doi.org/10.1016/j.jhydrol.2006.12.002

Arndt, S., Jørgensen, B.B., LaRowe, D.E., Middelburg, J.J., Pancost, R.D., Regnier, P., 2013. Quantifying the degradation of organic matter in marine sediments: A review and synthesis. Earth-Science Rev. 123, 53-86. https://doi.org/10.1016/J.EARSCIREV.2013.02.008

Benner, R., Biddanda, B., Black, B., McCarthy, M., 1997. Abundance, size distribution, and stable carbon and nitrogen isotopic compositions of marine organic matter isolated by tangential-flow ultrafiltration. Mar. $\quad$ Chem. 243-263. https://doi.org/http://dx.doi.org/10.1016/S0304-4203(97)00013-3

Bianchi, T.S., Canuel, E.A., 2011. Chemical Biomarkers in Aquatic Ecosystems. Princeton University Press, Princeton University.

Bischoff, J., Sparkes, R.B., Doğrul Selver, A., Spencer, R.G.M., Gustafsson, Ö., Semiletov, I.P., Dudarev, O. V., Wagner, D., Rivkina, E., van Dongen, B.E., Talbot, H.M., 2016. Source, transport and fate of soil organic matter inferred from microbial biomarker lipids on the East Siberian Arctic Shelf. Biogeosciences 13, 4899-4914. https://doi.org/10.5194/bg-134899-2016

Bouloubassi, I., Lipiatou, E., Saliot, A., Tolosa, I., Bayona, J.M.M., Albaigés, J., 1997. Carbon sources and cycle in the western Mediterranean-the use of molecular markers to determine the origin of organic matter. Deep Sea Res. Part II Top. Stud. Oceanogr. 44, 781-799. https://doi.org/https://doi.org/10.1016/S0967-0645(96)00094-X 
Briand, M.J., Bonnet, X., Goiran, C., Guillou, G., Letourneur, Y., 2015. Major Sources of Organic Matter in a Complex Coral Reef Lagoon: Identification from Isotopic Signatures $(\delta(13) \mathrm{C}$ and $\delta(15) \mathrm{N})$.

PLoS

One

10 , e0131555. https://doi.org/10.1371/journal.pone.0131555

Bull, I.D., Lockheart, M.J., Elhmmali, M.M., Roberts, D.J., Evershed, R.P., 2002. The origin of

Carabel, S., Godínez-Domínguez, E., Verísimo, P., Fernández, L., Freire, J., 2006. An assessment of sample processing methods for stable isotope analyses of marine food webs. J. Exp. Mar.

Bio. Ecol. 336 , 254-261. https://doi.org/http://dx.doi.org/10.1016/j.jembe.2006.06.001

Cawley, K.M., Ding, Y., Fourqurean, J., Jaffé, R., 2012. Characterising the sources and fate of dissolved organic matter in Shark Bay, Australia: a preliminary study using optical properties and stable carbon isotopes. Mar. Freshw. Res. 63, 1098-1107. https://doi.org/https://doi.org/10.1071/MF12028

D’Andrilli, J., Foreman, C.M., Sigl, M., Priscu, J.C., McConnell, J.R., 2017. A 21 000-year

Debieu, D., Gall, C., Gredt, M., Bach, J., Malosse, C., Leroux, P., 1992. Ergosterol biosynthesis

Derrien, M., Brogi, S.R., Gonçalves-Araujo, R., Retelletti Brogi, S., Gonçalves-Araujo, R., 2019a. Characterization of aquatic organic matter: Assessment, perspectives and research priorities. Water Res. 163, 114908. https://doi.org/10.1016/J.WATRES.2019.114908 
523 Derrien, M., Cabrera, F.A., Tavera, N.L.V., Kantún Manzano, C.A., Vizcaino, S.C., 2015.

524 Sources and distribution of organic matter along the Ring of Cenotes, Yucatan, Mexico:

525 Sterol markers and statistical approaches. Sci. Total Environ. 511.

$526 \quad$ https://doi.org/10.1016/j.scitotenv.2014.12.053

527 Derrien, M., Jardé, E., Gruau, G., Pierson-Wickmann, A.-C., 2011. Extreme variability of steroid

528 profiles in cow feces and pig slurries at the regional scale: Implications for the use of

529 steroids to specify fecal pollution sources in waters. J. Agric. Food Chem. 59.

$530 \quad$ https://doi.org/10.1021/jf201040v

531 Derrien, M., Kim, M.S., Ock, G., Hong, S., Cho, J., Shin, K.H.K.-H.K.H., Hur, J., 2018.

532 Estimation of different source contributions to sediment organic matter in an agricultural-

533 forested watershed using end member mixing analyses based on stable isotope ratios and

534 fluorescence spectroscopy. Sci. Total Environ. 618, 569-578.

$535 \quad$ https://doi.org/https://doi.org/10.1016/j.scitotenv.2017.11.067

536 Derrien, M., Shin, K.-H., Hur, J., 2019b. Assessment on applicability of common source tracking

537 tools for particulate organic matter in controlled end member mixing experiments. Sci.

$538 \quad$ Total Environ. 666, 187-196. https://doi.org/10.1016/j.scitotenv.2019.02.258

539 Derrien, M., Shin, K.-H., Hur, J., 2019c. Biodegradation-induced signatures in sediment pore

$540 \quad$ water dissolved organic matter: Implications from artificial sediments composed of two

$541 \quad$ contrasting sources. Sci. Total Environ. 694, 133714.

542 Derrien, M., Yang, L., Hur, J., 2017. Lipid biomarkers and spectroscopic indices for identifying

543 organic matter sources in aquatic environments: A review. Water Res. 112.

$544 \quad$ https://doi.org/10.1016/j.watres.2017.01.023

545 Fichot, C.G., Kaiser, K., Hooker, S.B., Amon, R.M.W., Babin, M., Bélanger, S., Walker, S.A., 
Benner, R., 2013. Pan-Arctic distributions of continental runoff in the Arctic Ocean 3, 1053. https://doi.org/10.1038/srep01053http://dharmasastra.live.cf.private.springer.com/articles/sr ep01053\#supplementary-information

549

Fisher, M.M., Reddy, K.R., James, R.T., 2005. Internal nutrient loads from sediments in a shallow, subtropical lake. Lake Reserv. Manag. 21, 338-349. https://doi.org/10.1080/07438140509354439

Galletti, Y., Gonnelli, M., Retelletti Brogi, S., Vestri, S., Santinelli, C., 2019. DOM dynamics in open waters of the Mediterranean Sea: New insights from optical properties. Deep. Res. Part I Oceanogr. Res. Pap. 144, 95-114. https://doi.org/10.1016/j.dsr.2019.01.007

Gordon, E.S., Goni, M.A., 2003. Sources and distribution of terrigenous organic matter delivered by the Atchafalaya River to sediments in the northern Gulf of Mexico. Geochim. Cosmochim. Acta 67, 2359-2375. https://doi.org/10.1016/S0016-7037(02)01412-6

Graeber, D., Gelbrecht, J., Pusch, M.T., Anlanger, C., von Schiller, D., 2012. Agriculture has changed the amount and composition of dissolved organic matter in Central European $\begin{array}{lllll}\text { headwater } & \text { streams. } & \text { Sci. } & \text { Total 435-446. }\end{array}$ https://doi.org/https://doi.org/10.1016/j.scitotenv.2012.08.087

Guenet, B., Danger, M., Harrault, L., Allard, B., Jauset-Alcala, M., Bardoux, G., Benest, D., Abbadie, L., Lacroix, G., 2014. Fast mineralization of land-born C in inland waters: first experimental evidences of aquatic priming effect. Hydrobiologia 721, 35-44. https://doi.org/10.1007/s10750-013-1635-1

Hansen, A.M., Kraus, T.E.C., Pellerin, B.A., Fleck, J.A., Downing, B.D., Bergamaschi, B.A., 2016. Optical properties of dissolved organic matter (DOM): Effects of biological and photolytic degradation. Limnol. Oceanogr. 61, 1015-1032. 
https://doi.org/10.1002/lno.10270

570 Harrault, L., Milek, K., Jardé, E., Jeanneau, L., Derrien, M., Anderson, D.G., 2019. Faecal biomarkers can distinguish specific mammalian species in modern and past environments.

573

574

575

576

577

578

579

580

581

582

583

584

585

586

587

588

589

590

591

PLoS One 14, e0211119. https://doi.org/10.1371/journal.pone.0211119

Harvey, R.H., Tuttle, J.H., Bell, T.J., 1995. Kinetics of phytoplankton decay during simulated sedimentation: Changes in biochemical composition and microbial activity under oxic and anoxic conditions. Geochim. Cosmochim. Acta 59, 3367-3377. https://doi.org/http://dx.doi.org/10.1016/0016-7037(95)00217-N

Henrichs, S.M., 1992. Early diagenesis of organic matter in marine sediments: progress and perplexity. Mar. Chem. 39, 119-149. https://doi.org/10.1016/0304-4203(92)90098-U

Heo, Y., Kim, D.-H., Lee, H., Lee, D., Her, Namguk, J., Yoon, 2016. A new fluorescence index with a fluorescence excitation-emission matrix for dissolved organic matter (DOM) characterization. Desalin. Water Treat. 57, 20270-20282. https://doi.org/10.1080/19443994.2015.1110719

Huguet, A., Vacher, L., Relexans, S., Saubusse, S., Froidefond, J.M., Parlanti, E., 2009. Properties of fluorescent dissolved organic matter in the Gironde Estuary. Org. Geochem. 40, 706-719. https://doi.org/https://doi.org/10.1016/j.orggeochem.2009.03.002

Jaffé, R., Boyer, J.N., Lu, X., Maie, N., Yang, C., Scully, N.M., Mock, S., 2004. Source characterization of dissolved organic matter in a subtropical mangrove-dominated estuary by fluorescence analysis. Mar. Chem. 84, 195-210. https://doi.org/https://doi.org/10.1016/j.marchem.2003.08.001

Kinsey, J.D., Corradino, G., Ziervogel, K., Schnetzer, A., Osburn, C.L., 2018. Formation of Chromophoric Dissolved Organic Matter by Bacterial Degradation of Phytoplankton- 
Derived Aggregates. Front. Mar. Sci. 4, 430. https://doi.org/10.3389/fmars.2017.00430

593 Kristensen, E., 2000. Organic matter diagenesis at the oxic/anoxic interface in coastal marine 594 sediments, with emphasis on the role of burrowing animals. Hydrobiologia 426, 1-24. $595 \quad$ https://doi.org/10.1023/A:1003980226194

Kuznetsova, O. V, Sevastyanov, V.S., Timerbaev, A.R., 2019. What are the current analytical

Li, P., Chen, L., Zhang, W., Huang, Q., 2015. Spatiotemporal Distribution, Sources, and Leeming, R., Nichols, P.D., 1998. Determination of the sources and distribution of sewage and pulp-fibre-derived pollution in the Derwent Estuary, Tasmania, using sterol biomarkers. Mar. Freshw. Res. 49, 7-17. https://doi.org/https://doi.org/10.1071/MF95140

Lehmann, M.F., Bernasconi, S.M., Barbieri, A., McKenzie, J.A., 2002. Preservation of organic matter and alteration of its carbon and nitrogen isotope composition during simulated and in situ early sedimentary diagenesis. Geochim. Cosmochim. Acta 66, 3573-3584. https://doi.org/http://dx.doi.org/10.1016/S0016-7037(02)00968-7

613 Meyers, P.A., Ishiwatari, R., 1993. Lacustrine organic geochemistry—an overview of indicators 614 of organic matter sources and diagenesis in lake sediments. Org. Geochem. 20, 867-900. 
616 Milliken, K.L., 2003. Late Diagenesis and Mass Transfer in Sandstone-Shale Sequences. 617 Treatise on Geochemistry 159-190. https://doi.org/10.1016/B0-08-043751-6/07091-2

618 Murphy, K.R., Stedmon, C.A., Graeber, D., Bro, R., 2013. Fluorescence spectroscopy and multi619 way techniques. PARAFAC. Anal. Methods 5, 6557-6566.

Navel, S., Mermillod-Blondin, F., Montuelle, B., Chauvet, E., Marmonier, P., 2012. Sedimentary context controls the influence of ecosystem engineering by bioturbators on microbial processes in river sediments. Oikos 121, 1134-1144. https://doi.org/doi:10.1111/j.16000706.2011.19742.x

Ogrinc, N., Fontolan, G., Faganeli, J., Covelli, S., 2005. Carbon and nitrogen isotope compositions of organic matter in coastal marine sediments (the Gulf of Trieste, N Adriatic Sea): indicators of sources and preservation. Mar. Chem. 95, 163-181. https://doi.org/http://dx.doi.org/10.1016/j.marchem.2004.09.003

Osburn, C.L., Boyd, T.J., Montgomery, M.T., Bianchi, T.S., Coffin, R.B., Paerl, H.W., 2016a. Optical Proxies for Terrestrial Dissolved Organic Matter in Estuaries and Coastal Waters.

635 Pardue, J.W., Scalan, R.S., Van Baalen, C., Parker, P.L., 1976. Maximum carbon isotope 636 fractionation in photosynthesis by blue-green algae and a green alga. Geochim. Cosmochim. 637 Acta 40, 309-312. https://doi.org/https://doi.org/10.1016/0016-7037(76)90208-8 
638 Park, M., Snyder, S.A., 2018. Sample handling and data processing for fluorescent excitationemission matrix (EEM) of dissolved organic matter (DOM). Chemosphere 193, 530-537. https://doi.org/https://doi.org/10.1016/j.chemosphere.2017.11.069

641

642

643

644

645

646

647

648

649

650

651

652

653

654

655

656

657

658

659

660

Pedrosa-Pàmies, R., Parinos, C., Sanchez-Vidal, A., Gogou, A., Calafat, A., Canals, M., Bouloubassi, I., Lampadariou, N., 2015. Composition and sources of sedimentary organic matter in the deep eastern Mediterranean Sea. Biogeosciences 12, 7379-7402. https://doi.org/10.5194/bg-12-7379-2015

Retelletti Brogi, S., Derrien, M., Hur, J., 2019a. In-Depth Assessment of the Effect of Sodium Azide on the Optical Properties of Dissolved Organic Matter. J. Fluoresc. 1-9. https://doi.org/10.1007/s10895-019-02398-w

Retelletti Brogi, S., Kim, J.-H., Ryu, J.-S., Jin, Y.K., Lee, Y.K., Hur, J., 2019b. Exploring sediment porewater dissolved organic matter (DOM) in a mud volcano: Clues of a thermogenic DOM source from fluorescence spectroscopy. Mar. Chem. https://doi.org/10.1016/J.MARCHEM.2019.03.009

Shah, V.G.., Dunstan, R.H.., Geary, P.M.., Coombes, P.., Roberts, T.K.., Von Nagy-Felsobuki, E., 2007. Evaluating potential applications of faecal sterols in distinguishing sources of faecal contamination from mixed faecal samples. Water Res. 41, 3691-3700. https://doi.org/10.1016/j.watres.2007.04.006

Sillanpää, M., 2015. Natural Organic Matter in Water: Characterization and Treatment Methods, Natural Organic Matter in Water: Characterization and Treatment Methods. Elsevier Inc. https://doi.org/10.1016/C2013-0-19213-6

Southwell, M.W., Kieber, R.J., Mead, R.N., Avery, G.B., Skrabal, S.A., 2010. Effects of sunlight on the production of dissolved organic and inorganic nutrients from resuspended sediments. 
662 Toming, K., Tuvikene, L., Vilbaste, S., Agasild, H., Viik, M., Kisand, A., Feldmann, T., Martma, T., Jones, R.I., Nõges, T., 2013. Contributions of autochthonous and allochthonous sources

van der Meij, W.M., Temme, A.J.A.M., Lin, H.S., Gerke, H.H., Sommer, M., 2018. On the role of hydrologic processes in soil and landscape evolution modeling: concepts, complications and partial solutions. Earth-Science Rev. https://doi.org/10.1016/j.earscirev.2018.09.001

Volkman, J.K., 2005. Sterols and other triterpenoids: source specificity and evolution of

Volkman, J.K., Tanoue, E., 2002. Chemical and Biological Studies of Particulate Organic Matter

Vonk, J.E., Tank, S.E., Mann, P.J., Spencer, R.G.M., Treat, C.C., Striegl, R.G., Abbott, B.W., Wickland, K.P., 2015. Biodegradability of dissolved organic carbon in permafrost soils and aquatic systems: a meta-analysis.

Biogeosciences

12 ,

6915-6930. https://doi.org/10.5194/bg-12-6915-2015

678 Wakeham, S.G., Canuel, E.A., 1990. Fatty acids and sterols of particulate matter in a brackish and seasonally anoxic coastal salt pond. Org. Geochem. 16, 703-713. https://doi.org/http://dx.doi.org/10.1016/0146-6380(90)90111-C

681 Waterson, E.J., Canuel, E.A., 2008. Sources of sedimentary organic matter in the Mississippi 682 River and adjacent Gulf of Mexico as revealed by lipid biomarker and $\delta 13 \mathrm{CTOC}$ analyses. 683 Org. Geochem.

39, 422-439. 
https://doi.org/https://doi.org/10.1016/j.orggeochem.2008.01.011

685

686

687

688

\section{9}

690

691

692

693

694

695

696

697

698

699

700

701

702

703

704

705

706

Wild, B., Andersson, A., Bröder, L., Vonk, J., Hugelius, G., McClelland, J.W., Song, W., Raymond, P.A., Gustafsson, Ö., 2019. Rivers across the Siberian Arctic unearth the patterns of carbon release from thawing permafrost. Proc. Natl. Acad. Sci. U. S. A. 116, 1028010285. https://doi.org/10.1073/pnas.1811797116

Wünsch, U.J., Murphy, K.R., Stedmon, C.A., 2017. The One-Sample PARAFAC Approach Reveals Molecular Size Distributions of Fluorescent Components in Dissolved Organic Matter. Environ. Sci. Technol. https://doi.org/10.1021/acs.est.7b03260

Xiao, H.-Y., Liu, C.-Q., 2010. Identifying organic matter provenance in sediments using isotopic ratios in an urban river. Geochem. J. 44, 181-187. https://doi.org/10.2343/geochemj.1.0059

Yamashita, Y., Boyer, J.N., Jaffé, R., 2013. Evaluating the distribution of terrestrial dissolved organic matter in a complex coastal ecosystem using fluorescence spectroscopy. Cont. Shelf Res. 66, 136-144. https://doi.org/http://dx.doi.org/10.1016/j.csr.2013.06.010

Yamashita, Y., Maie, N., Briceño, H., Jaffé, R., 2010. Optical characterization of dissolved organic matter in tropical rivers of the Guayana Shield, Venezuela. J. Geophys. Res. Biogeosciences 115, n/a-n/a. https://doi.org/10.1029/2009JG000987

Yu, Z.T., Wang, X.J., Zhang, E.L., Zhao, C.Y., Liu, X.Q., 2015. Spatial distribution and sources of organic carbon in the surface sediment of Bosten Lake, China. Biogeosciences 12, 66056615. https://doi.org/10.5194/bg-12-6605-2015

Zhang, L., Yin, K., Wang, L., Chen, F., Zhang, D., Yang, Y., 2009. The sources and accumulation rate of sedimentary organic matter in the Pearl River Estuary and adjacent coastal area, Southern China. Estuar. Coast. Shelf Sci. 85, 190-196. https://doi.org/10.1016/j.ecss.2009.07.035 
707 Zhang, Y., Su, Y., Liu, Z., Yu, J., Jin, M., 2017. Lipid biomarker evidence for determining the 708 origin and distribution of organic matter in surface sediments of Lake Taihu, Eastern China. 709 Ecol. Indic. 77, 397-408. https://doi.org/https://doi.org/10.1016/j.ecolind.2017.02.031

710 Zimmerman, A.R., Canuel, E.A., 2001. Bulk Organic Matter and Lipid Biomarker Composition 711 of Chesapeake Bay Surficial Sediments as Indicators of Environmental Processes. Estuar. 712 Coast. Shelf Sci. 53, 319-341. https://doi.org/http://dx.doi.org/10.1006/ecss.2001.0815

713 Zsolnay, A., Baigar, E., Jimenez, M., Steinweg, B., Saccomandi, F., 1999. Differentiating with 714 fluorescence spectroscopy the sources of dissolved organic matter in soils subjected to 715 drying. Chemosphere 38, 45-50. https://doi.org/http://dx.doi.org/10.1016/S0045$716 \quad 6535(98) 00166-0$ 
Figure 1. Relative abundances (\%) of the four different fluorescent components (C1-C4) in the artificial sediments at five different mixing ratios of two end-members (i.e., soil and algae) under oxic and anoxic conditions at the incubation time of 0 and 60 days. The lines and dashed lines represent the evolution of the parameters with varying mixing ratios of the two end-members.

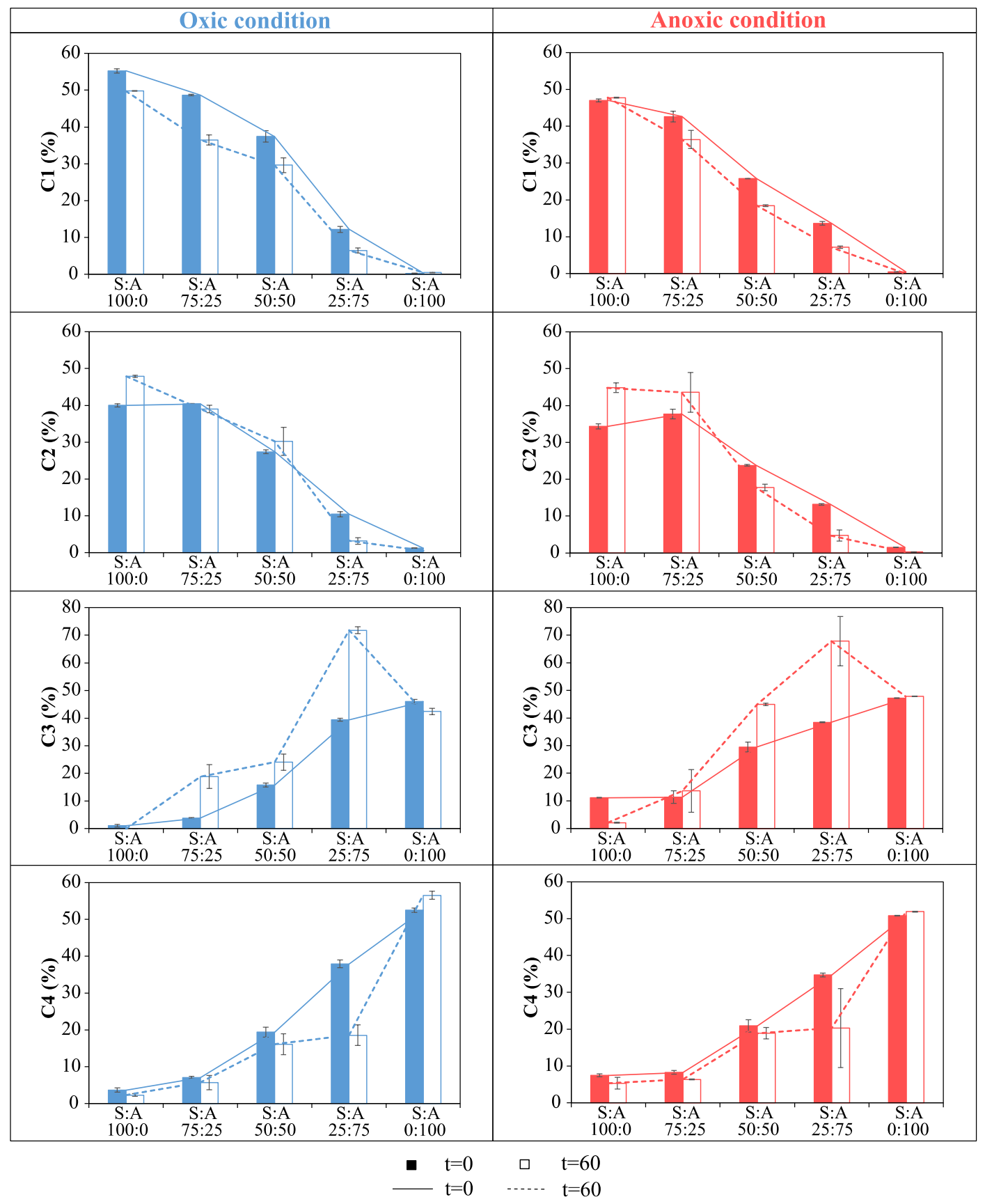


Figure 2. Values of the absorbance and fluorescent indices SUVA (a), FI (b), YFI (c), HIX (d), and BIX (e) in the artificial sediments at five different mixing ratios of two end-members (i.e., soil and algae) under oxic and anoxic conditions at the incubation time of 0 and 60 days. The blue color is used for the data of oxic conditions while pink color for those of anoxic conditions.

a.

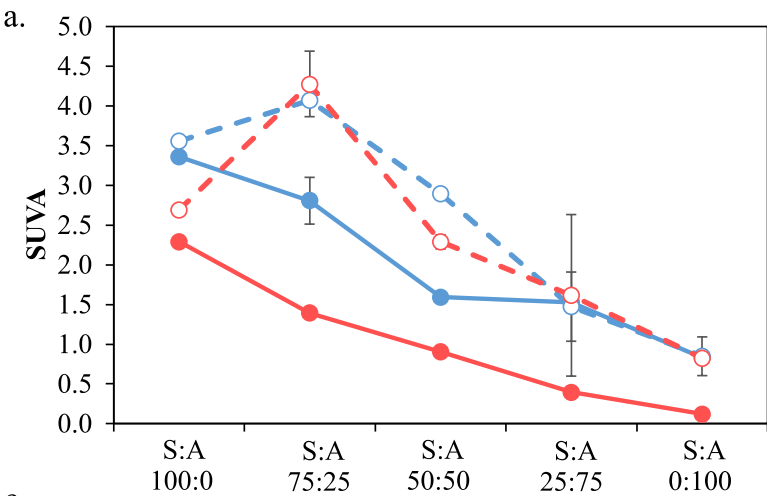

c.
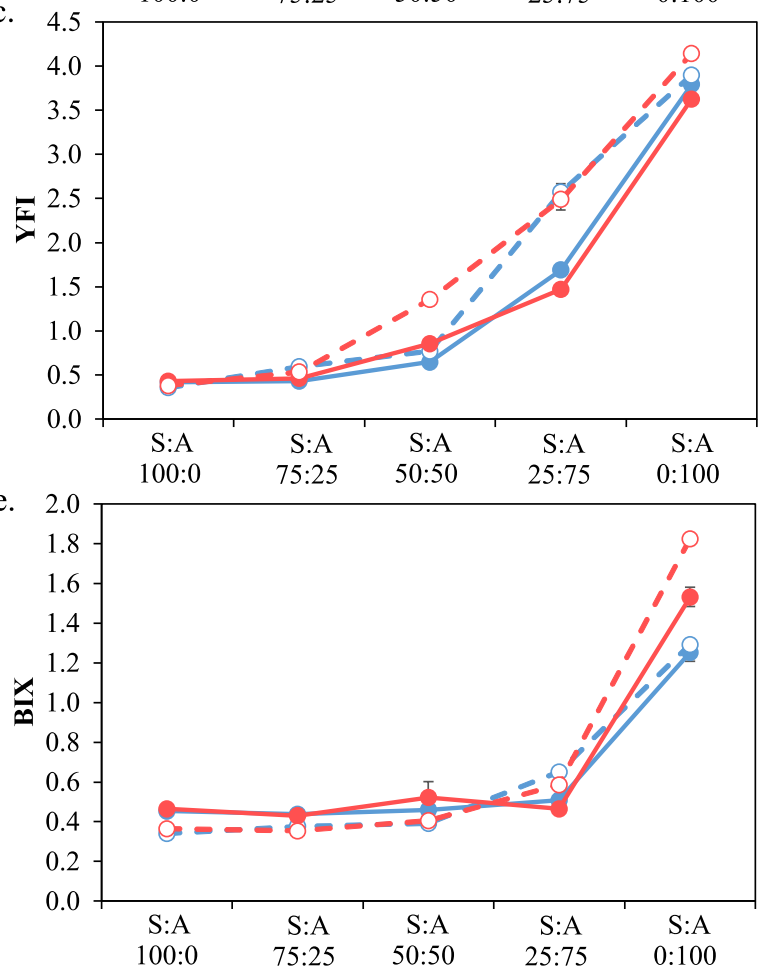

b.

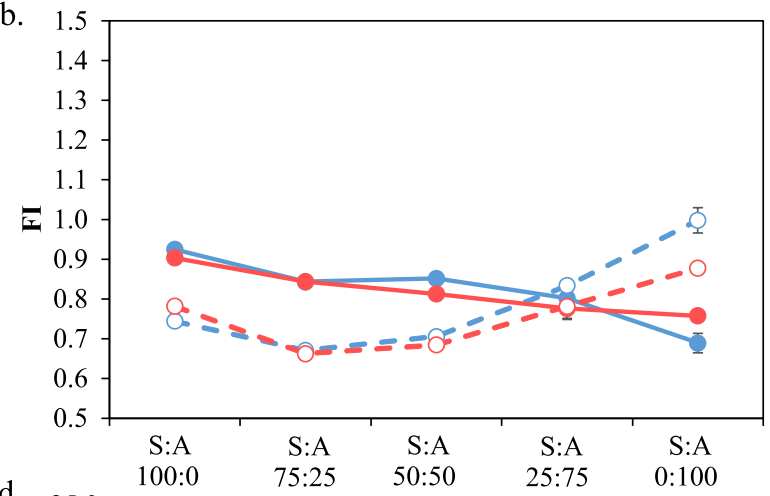

d.

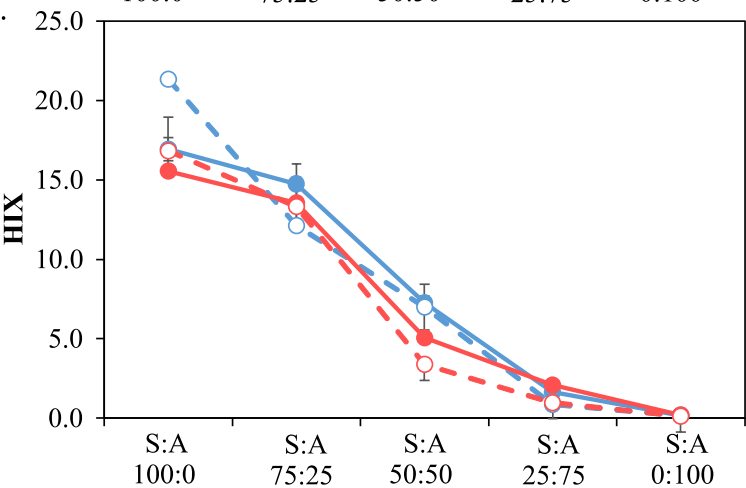

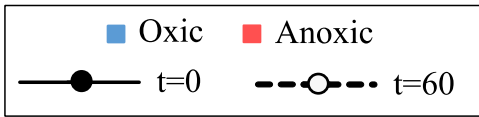


Figure 3. Values of the carbon stable isotopes in the artificial sediments at five different mixing ratios of two end-members (i.e., soil and algae) under oxic and anoxic conditions at the incubation time of 0 and 60 days. The blue color is used for the data of oxic conditions while pink color for those of anoxic conditions.

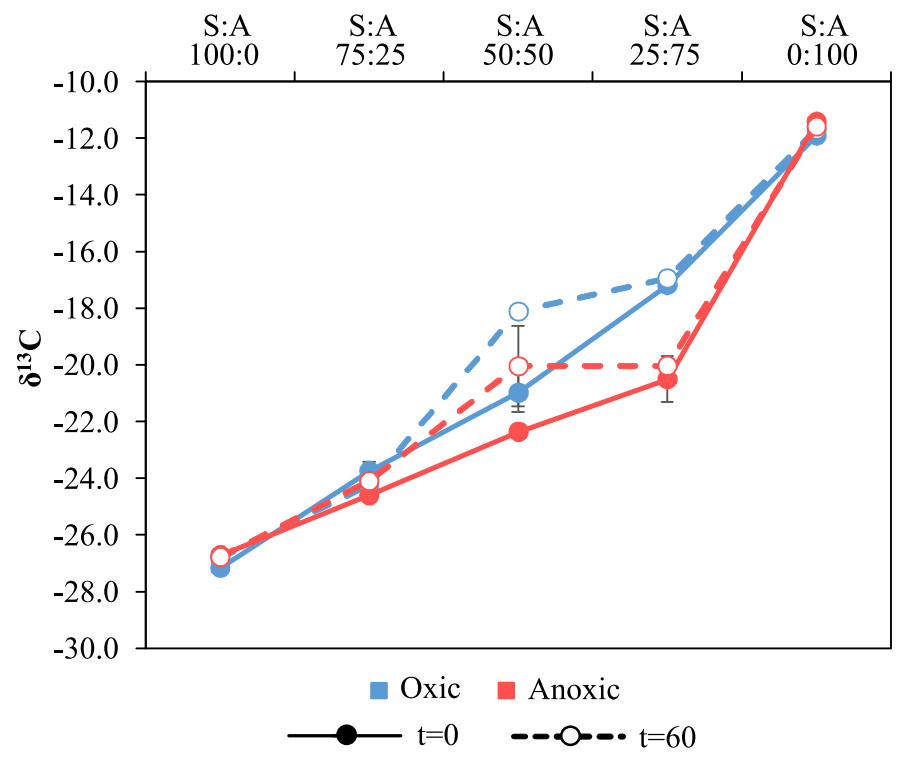


Figure 4. Relative abundances (\%) of the seven sterols/stanols in the artificial sediments at five different mixing ratios of two end-members (i.e., soil and algae) under oxic and anoxic conditions at the incubation time of 0 and 60 days. The lines and dashed lines represent the evolution of the parameters with varying mixing ratios of the two end-members. 


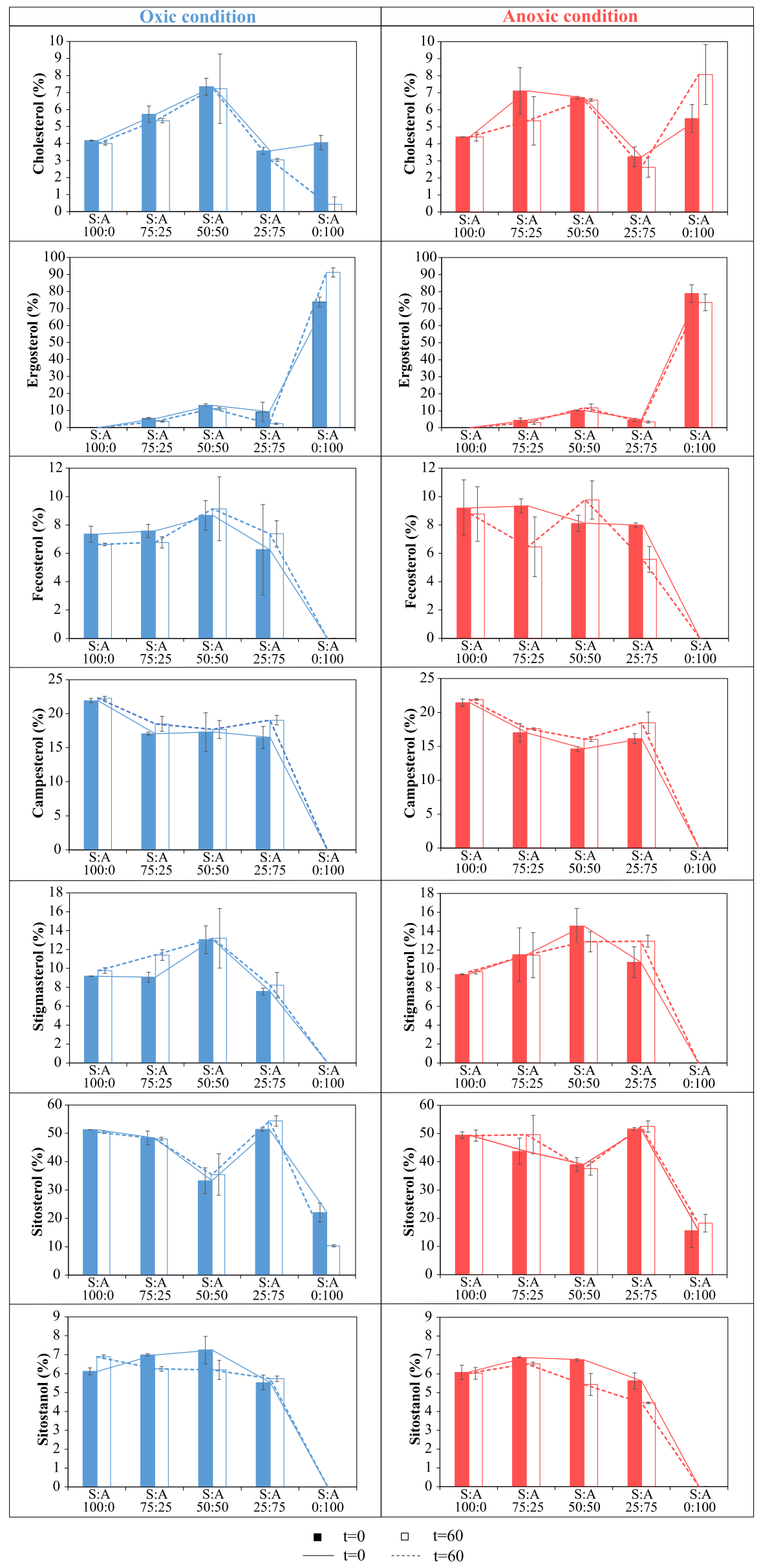


Table 1. The relative changes of the 4 identified components (\%) and the spectroscopic indices, the carbon stable isotopic ratios (\%o) and the distribution in the sterols/stanols in the artificial sediment of the two end-members before versus after incubation under oxic and anoxic conditions (average values \pm standard deviation).

\begin{tabular}{|c|c|c|c|c|c|c|c|c|c|}
\hline & \multicolumn{4}{|c|}{ Soil end-member } & \multicolumn{4}{|c|}{ Algae end-member } \\
\hline & & \multicolumn{2}{|c|}{ Oxic } & \multicolumn{2}{|c|}{ Anoxic } & \multicolumn{2}{|c|}{ Oxic } & \multicolumn{2}{|c|}{ Anoxic } \\
\hline & & $\begin{array}{c}0 \text { day- } \\
\text { incubation }\end{array}$ & $\begin{array}{l}60 \text { days- } \\
\text { incubation }\end{array}$ & $\begin{array}{c}0 \text { day- } \\
\text { incubation }\end{array}$ & $\begin{array}{l}60 \text { days- } \\
\text { incubation }\end{array}$ & $\begin{array}{c}0 \text { day- } \\
\text { incubation }\end{array}$ & $\begin{array}{l}60 \text { days- } \\
\text { incubation }\end{array}$ & $\begin{array}{c}0 \text { day- } \\
\text { incubation }\end{array}$ & $\begin{array}{l}60 \text { days- } \\
\text { incubation }\end{array}$ \\
\hline \multirow{9}{*}{ 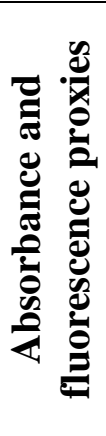 } & C1 (\%) & $55.2 \pm 0.6$ & $49.8 \pm 0.1$ & $47.0 \pm 0.4$ & $47.7 \pm 0.1$ & $0.3 \pm 0.1$ & $0.5 \pm 0.0$ & $0.5 \pm 0.0$ & $0.0 \pm 0.0$ \\
\hline & C2 (\%) & $40.0 \pm 0.4$ & $47.9 \pm 0.3$ & $34.4 \pm 0.7$ & $44.8 \pm 1.3$ & $1.2 \pm 0.1$ & $0.6 \pm 0.0$ & $1.5 \pm 0.0$ & $0.2 \pm 0.0$ \\
\hline & C3 (\%) & $1.1 \pm 0.5$ & $0.0 \pm 0.0$ & $11.2 \pm 0.1$ & $2.1 \pm 0.1$ & $46.0 \pm 0.8$ & $42.4 \pm 1.1$ & $47.2 \pm 0.1$ & $47.8 \pm 0.1$ \\
\hline & C4 (\%) & $3.7 \pm 0.5$ & $2.3 \pm 0.3$ & $7.5 \pm 0.4$ & $5.3 \pm 1.6$ & $52.5 \pm 0.6$ & $56.5 \pm 1.1$ & $50.8 \pm 0.1$ & $51.9 \pm 0.1$ \\
\hline & $\operatorname{SUVA}_{254}\left(\mathrm{~L} \cdot \mathrm{mg}^{-1} \cdot \mathrm{m}^{-1}\right)$ & $3.4 \pm 0.1$ & $3.6 \pm 0.1$ & $2.3 \pm 0.0$ & $2.7 \pm 0.1$ & $0.8 \pm 0.1$ & $0.8 \pm 0.2$ & $0.1 \pm 0.0$ & $0.8 \pm 0.0$ \\
\hline & FI & $0.9 \pm 0.0$ & $0.7 \pm 0.0$ & $0.9 \pm 0.0$ & $0.8 \pm 0.0$ & $0.7 \pm 0.0$ & $1.0 \pm 0.0$ & $0.8 \pm 0.0$ & $0.9 \pm 0.0$ \\
\hline & YFI & $0.4 \pm 0.0$ & $0.4 \pm 0.0$ & $0.4 \pm 0.0$ & $0.4 \pm 0.0$ & $3.8 \pm 0.0$ & $3.9 \pm 0.0$ & $3.6 \pm 0.0$ & $4.1 \pm 0.0$ \\
\hline & HIX & $16.9 \pm 0.7$ & $21.3 \pm 0.2$ & $15.6 \pm 0.4$ & $16.8 \pm 2.1$ & $0.2 \pm 0.0$ & $0.2 \pm 0.0$ & $0.2 \pm 0.0$ & $0.1 \pm 0.0$ \\
\hline & BIX & $0.5 \pm 0.0$ & $0.3 \pm 0.0$ & $0.5 \pm 0.0$ & $0.4 \pm 0.0$ & $1.3 \pm 0.0$ & $1.3 \pm 0.0$ & $1.5 \pm 0.0$ & $1.8 \pm 0.0$ \\
\hline $\begin{array}{l}\mathscr{Q} \\
\stackrel{0}{0} \\
\stackrel{0}{0} \\
\stackrel{\omega}{0}\end{array}$ & $\delta^{13} \mathrm{C}(\%$ (\%) & $-27.2 \pm 0.1$ & $-26.8 \pm 0.1$ & $-26.7 \pm 0.1$ & $-26.8 \pm 0.1$ & $-11.9 \pm 0.0$ & $-11.7 \pm 0.0$ & $-11.4 \pm 0.1$ & $-11.6 \pm 0.1$ \\
\hline \multirow{7}{*}{ 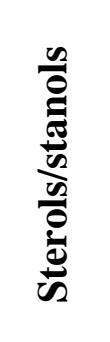 } & Cholesterol (\%) & $4.2 \pm 0.0$ & $4.0 \pm 0.1$ & $4.4 \pm 0.0$ & $4.4 \pm 0.2$ & $4.1 \pm 0.4$ & $0.4 \pm 0.4$ & $5.5 \pm 0.8$ & $8.1 \pm 1.8$ \\
\hline & Ergosterol (\%) & $0.0 \pm 0.0$ & $0.0 \pm 0.0$ & $0.0 \pm 0.0$ & $0.0 \pm 0.0$ & $73.9 \pm 2.9$ & $91.1 \pm 2.7$ & $78.9 \pm 5.2$ & $73.6 \pm 4.9$ \\
\hline & Fecosterol (\%) & $7.4 \pm 0.6$ & $6.6 \pm 0.1$ & $9.2 \pm 2.0$ & $8.8 \pm 1.9$ & $0.0 \pm 0.0$ & $0.0 \pm 0.0$ & $0.0 \pm 0.0$ & $0.0 \pm 0.0$ \\
\hline & Campesterol (\%) & $21.9 \pm 0.3$ & $22.3 \pm 0.3$ & $21.5 \pm 0.5$ & $21.9 \pm 0.1$ & $0.0 \pm 0.0$ & $0.0 \pm 0.0$ & $0.0 \pm 0.0$ & $0.0 \pm 0.0$ \\
\hline & Stigmasterol (\%) & $9.2 \pm 0.0$ & $9.8 \pm 0.3$ & $9.4 \pm 0.0$ & $9.7 \pm 0.2$ & $0.0 \pm 0.0$ & $0.0 \pm 0.0$ & $0.0 \pm 0.0$ & $0.0 \pm 0.0$ \\
\hline & Sitosterol (\%) & $51.3 \pm 0.1$ & $50.4 \pm 0.5$ & $49.1 \pm 1.1$ & $49.2 \pm 2.0$ & $22.1 \pm 3.3$ & $10.3 \pm 0.4$ & $15.6 \pm 6.0$ & $18.3 \pm 3.1$ \\
\hline & Sitostanol (\%) & $6.1 \pm 0.2$ & $6.9 \pm 0.1$ & $6.1 \pm 0.4$ & $6.0 \pm 0.3$ & $0.0 \pm 0.0$ & $0.0 \pm 0.0$ & $0.0 \pm 0.0$ & $0.0 \pm 0.0$ \\
\hline
\end{tabular}


Table 2. The evaluation of selected source discrimination indices in the relationships with increasing algal carbon fraction (\% Algae) of the artificial sediments at 0-day incubation.

\begin{tabular}{|c|c|c|c|c|c|c|c|c|c|}
\hline Parameters & $\begin{array}{l}\text { Oxygen } \\
\text { condition }\end{array}$ & Tendency & $\begin{array}{l}\text { Relationship } \\
\text { type }^{\mathrm{a}}\end{array}$ & $\mathrm{R}^{2}$ (p-value) & $\mathrm{S}_{\mathrm{m}}^{\mathrm{b}}$ & $\mathrm{S}_{\mathrm{m}} / \mathrm{SD}^{\mathrm{c}}$ & $\mathrm{S}_{\mathrm{p}}{ }^{\mathrm{d}}$ & $\%$ difference $\mathrm{e}^{\mathrm{e}}$ & Applicability \\
\hline \multicolumn{10}{|l|}{ Extractable OM } \\
\hline \multirow[t]{2}{*}{ C1 (\%) } & Oxic & $\downarrow$ & Linear & $0.958(<0.01)$ & 0.585 & 0.905 & 0.550 & 6.5 & 000 \\
\hline & Anoxic & $\downarrow$ & Linear & $0.979(<0.01)$ & 0.488 & 0.992 & 0.465 & 4.9 & 000 \\
\hline \multirow[t]{2}{*}{ C2 (\%) } & Oxic & $\downarrow$ & Linear & $0.933(<0.01)$ & 0.430 & 1.159 & 0.388 & 10.9 & OOX \\
\hline & Anoxic & $\downarrow$ & Linear & $0.904(<0.01)$ & 0.361 & 0.752 & 0.328 & 9.9 & 000 \\
\hline \multirow[t]{2}{*}{ C3 (\%) } & Oxic & $\uparrow$ & Linear & $0.935(<0.01)$ & 0.501 & 0.917 & 0.449 & 11.7 & OOX \\
\hline & Anoxic & $\uparrow$ & Linear & $0.946(<0.01)$ & 0.397 & 0.443 & 0.360 & 10.1 & OXX \\
\hline \multirow[t]{2}{*}{ C4 (\%) } & Oxic & $\uparrow$ & Linear & $0.956(<0.01)$ & 0.514 & 0.668 & 0.488 & 5.3 & 000 \\
\hline & Anoxic & $\uparrow$ & Linear & $0.939(<0.01)$ & 0.452 & 0.713 & 0.433 & 4.4 & 000 \\
\hline \multirow[t]{2}{*}{ SUVA254 (L.mg $\left.{ }^{-1} \cdot \mathrm{m}^{-1}\right)$} & Oxic & $\downarrow$ & Linear & $0.944(<0.01)$ & 0.025 & 0.258 & 0.025 & 0.3 & OXX \\
\hline & Anoxic & $\downarrow$ & Linear & $0.961(<0.01)$ & 0.021 & 1.433 & 0.022 & 1.6 & 000 \\
\hline \multirow[t]{2}{*}{ FI } & Oxic & $\downarrow$ & Linear & $\mathbf{0 . 8 7 7}(0.019)$ & 0.002 & 0.290 & 0.002 & 13.0 & OXX \\
\hline & Anoxic & $\downarrow$ & Linear & $0.964(<0.01)$ & 0.001 & 0.137 & 0.001 & 1.5 & OXO \\
\hline \multirow[t]{2}{*}{ YFI } & Oxic & $\uparrow$ & Nonlinear & $0.775(0.049)$ & 0.032 & 1.419 & 0.034 & 5.0 & XOO \\
\hline & Anoxic & $\uparrow$ & Nonlinear & $0.774(0.049)$ & 0.030 & 3.006 & 0.032 & 7.4 & XOO \\
\hline \multirow[t]{2}{*}{ HIX } & Oxic & $\downarrow$ & Linear & $0.956(<0.01)$ & 0.186 & 0.551 & 0.168 & 11.3 & OOX \\
\hline & Anoxic & $\downarrow$ & Linear & $0.937(<0.01)$ & 0.169 & 0.471 & 0.154 & 9.9 & OXO \\
\hline \multirow[t]{2}{*}{ BIX } & Oxic & $\uparrow$ & Nonlinear & $0.558(0.147)$ & 0.007 & 0.361 & 0.008 & 16.5 & XXX \\
\hline & Anoxic & $\uparrow$ & Nonlinear & $0.519(0.170)$ & 0.009 & 0.262 & 0.011 & 18.7 & XXX \\
\hline \multirow[t]{2}{*}{$\delta^{13} \mathrm{C}(\%)$} & Oxic & $\uparrow$ & Linear & $0.985(<0.01)$ & 0.148 & 0.660 & 0.153 & 2.8 & 000 \\
\hline & Anoxic & $\uparrow$ & Linear & $\mathbf{0 . 8 6 3}(0.023)$ & 0.139 & 0.481 & 0.153 & 9.3 & OXO \\
\hline \multirow[t]{2}{*}{ Cholesterol (\%) } & Oxic & $\downarrow$ & Nonlinear & $0.059(0.694)$ & 0.010 & 0.029 & 0.001 & 726.5 & XXX \\
\hline & Anoxic & $\downarrow$ & Nonlinear & $0.028(0.787)$ & 0.007 & 0.012 & 0.011 & 163.2 & XXX \\
\hline \multirow[t]{2}{*}{ Ergosterol (\%) } & Oxic & $\uparrow$ & Nonlinear & $0.625(0.111)$ & 0.607 & 0.299 & 0.739 & 17.8 & XXX \\
\hline & Anoxic & $\uparrow$ & Nonlinear & $0.562(0.144)$ & 0.632 & 0.418 & 0.789 & 19.9 & XXX \\
\hline \multirow[t]{2}{*}{ Fecosterol (\%) } & Oxic & $\downarrow$ & Nonlinear & $0.541(0.157)$ & 0.064 & 0.061 & 0.074 & 12.8 & XXX \\
\hline & Anoxic & $\downarrow$ & Nonlinear & $0.635(0.107)$ & 0.079 & 0.123 & 0.092 & 14.1 & XXX \\
\hline \multirow[t]{2}{*}{ Campesterol (\%) } & Oxic & $\downarrow$ & Nonlinear & $0.695(0.079)$ & 0.178 & 0.179 & 0.219 & 19.0 & XXX \\
\hline & Anoxic & $\downarrow$ & Nonlinear & $0.722(0.068)$ & 0.175 & 0.300 & 0.215 & 18.4 & XXX \\
\hline
\end{tabular}




\begin{tabular}{llllllllll} 
Stigmasterol (\%) & Oxic & $\downarrow$ & Nonlinear & $0.429(0.230)$ & 0.079 & 0.167 & 0.092 & 13.5 & XXX \\
& Anoxic & $\downarrow$ & Nonlinear & $0.319(0.321)$ & 0.079 & 0.061 & 0.094 & 16.6 & XXX \\
Sitosterol (\%) & Oxic & $\downarrow$ & Nonlinear & $0.447(0.217)$ & 0.221 & 0.101 & 0.292 & 24.1 & XXX \\
& Anoxic & $\downarrow$ & Nonlinear & $0.428(0.231)$ & 0.239 & 0.080 & 0.338 & 29.4 & XXX \\
Sitostanol (\%) & Oxic & $\downarrow$ & Nonlinear & $0.530(0.163)$ & 0.055 & 0.200 & 0.061 & 10.4 & XXX \\
& Anoxic & $\downarrow$ & Nonlinear & $0.544(0.155)$ & 0.054 & 0.296 & 0.061 & 11.8 & XXX \\
\hline
\end{tabular}

a: The relationship is considered linear for $\mathrm{R}^{2}>0.8$ with a $p$-value $<0.01$.

b: The absolute value of the regression slope for the measured values.

c: The absolute value of the regression slope for the measured values divided by the average standard deviation of the measurement. A value of the $\mathrm{S}_{\mathrm{m}} / \mathrm{SD}$ superior to 1.0 was considered as an acceptable sensitivity in the source discrimination relative to the measurement uncertainty

d: The absolute value of the regression slope for the predicted values (e.g., data presented in Table S2).

e: The difference (\%) between the slope of the measured and predicted values. A difference of $<10 \%$ is considered an acceptable deviation. The value of $10 \%$ was arbitrarily chosen by the authors.

${ }^{\mathrm{f}}$ : The applicability is evaluated via the criteria based on $\mathrm{R}^{2}, \mathrm{~S}_{\mathrm{m}} / \mathrm{SD}$, and \% difference. O means the value of the standard respect the critical value while $\mathrm{X}$ the indices failed (e.g., Critical values for $\mathrm{R}^{2}$ and an associated $\mathrm{p}$-value of $\mathrm{R}^{2}, \mathrm{~S}_{\mathrm{m}} / \mathrm{SD}$ and $\%$ difference are $>$ 0.8 and $<0.01,>0.5$, and $<10 \%$, respectively). 
Table 3. The evaluation of selected source discrimination indices in the relationships with increasing algal carbon fraction (\% Algae) of the artificial sediments at 60-days incubation.

\begin{tabular}{|c|c|c|c|c|c|c|c|c|c|}
\hline Parameters & $\begin{array}{l}\text { Oxygen } \\
\text { condition }\end{array}$ & Tendency & $\begin{array}{c}\text { Relationship } \\
\text { type }^{\text {a }}\end{array}$ & $\mathrm{R}^{2}$ (p-value) & $\mathrm{S}_{\mathrm{m}}{ }^{\mathrm{b}}$ & $\mathrm{S}_{\mathrm{m}} / \mathrm{SD}^{\mathrm{c}}$ & $\mathrm{S}_{\mathrm{p}}{ }^{\mathrm{d}}$ & $\%$ difference $\mathrm{e}^{\mathrm{e}}$ & Applicability $^{f}$ \\
\hline \multicolumn{10}{|l|}{ Extractable OM } \\
\hline \multirow[t]{2}{*}{ C1 (\%) } & Oxic & $\downarrow$ & Linear & $0.967(<0.01)$ & 0.514 & 0.614 & 0.493 & 4.4 & 000 \\
\hline & Anoxic & $\downarrow$ & Linear & $0.980(<0.01)$ & 0.499 & 0.795 & 0.477 & 4.5 & 000 \\
\hline \multirow[t]{2}{*}{ C2 (\%) } & Oxic & $\downarrow$ & Linear & $0.937(<0.01)$ & 0.522 & 0.439 & 0.473 & 10.3 & OXX \\
\hline & Anoxic & $\downarrow$ & Linear & $0.922(<0.01)$ & 0.512 & 0.281 & 0.446 & 14.9 & OXX \\
\hline \multirow[t]{2}{*}{ C3 (\%) } & Oxic & $\uparrow$ & Linear & $0.643(0.103)$ & 0.551 & 0.284 & 0.424 & 30.0 & XXX \\
\hline & Anoxic & $\uparrow$ & Linear & $0.737(0.063)$ & 0.582 & 0.168 & 0.457 & 27.5 & XXX \\
\hline \multirow[t]{2}{*}{ C4 (\%) } & Oxic & $\uparrow$ & Linear & $0.787(0.045)$ & 0.485 & 0.268 & 0.542 & 10.5 & XXX \\
\hline & Anoxic & $\uparrow$ & Linear & $\mathbf{0 . 8 0 9}(0.038)$ & 0.429 & 0.152 & 0.466 & 8.0 & OXO \\
\hline \multirow[t]{2}{*}{ SUVA254 (L.mg $\left.{ }^{-1} \cdot \mathrm{m}^{-1}\right)$} & Oxic & $\downarrow$ & Linear & $0.856(0.024)$ & 0.032 & 0.192 & 0.027 & 18.4 & OXX \\
\hline & Anoxic & $\downarrow$ & Nonlinear & $0.611(0.118)$ & 0.026 & 0.080 & 0.019 & 36.9 & XXX \\
\hline \multirow[t]{2}{*}{ FI } & Oxic & $\uparrow$ & Nonlinear & $0.654(0.097)$ & 0.003 & 0.200 & 0.003 & 5.7 & XXO \\
\hline & Anoxic & $\uparrow$ & Nonlinear & $0.321(0.319)$ & 0.001 & 0.112 & 0.001 & 29.8 & XXX \\
\hline \multirow[t]{2}{*}{ YFI } & Oxic & $\uparrow$ & Linear & $\mathbf{0 . 8 6 7}(0.021)$ & 0.036 & 0.682 & 0.035 & 2.3 & 000 \\
\hline & Anoxic & $\uparrow$ & Linear & $0.919(<0.01)$ & 0.038 & 0.688 & 0.038 & 0.8 & 000 \\
\hline \multirow[t]{2}{*}{ HIX } & Oxic & $\downarrow$ & Linear & $0.934(<0.01)$ & 0.214 & 0.542 & 0.212 & 1.3 & 000 \\
\hline & Anoxic & $\downarrow$ & Linear & $\mathbf{0 . 8 9 8}(0.014)$ & 0.183 & 0.169 & 0.167 & 9.5 & OXO \\
\hline \multirow[t]{2}{*}{ BIX } & Oxic & $\uparrow$ & Nonlinear & $0.739(0.062)$ & 0.009 & 0.534 & 0.010 & 8.5 & XOX \\
\hline & Anoxic & $\uparrow$ & Nonlinear & $0.622(0.113)$ & 0.013 & 1.202 & 0.015 & 13.6 & $\mathrm{XOX}$ \\
\hline \multirow[t]{2}{*}{$\delta^{13} \mathrm{C}(\%)$} & Oxic & $\uparrow$ & Linear & $0.969(<0.01)$ & 0.150 & 1.431 & 0.151 & 0.7 & 000 \\
\hline & Anoxic & $\uparrow$ & Nonlinear & $\mathbf{0 . 8 9 8}(0.014)$ & 0.138 & 0.274 & 0.152 & 9.3 & OXO \\
\hline \multirow[t]{2}{*}{ Cholesterol (\%) } & Oxic & $\downarrow$ & Nonlinear & $0.346(0.297)$ & 0.038 & 0.068 & 0.036 & 5.8 & XXO \\
\hline & Anoxic & $\downarrow$ & Nonlinear & $0.123(0.563)$ & 0.018 & 0.022 & 0.037 & 49.8 & XXX \\
\hline \multirow[t]{2}{*}{ Ergosterol (\%) } & Oxic & $\uparrow$ & Nonlinear & $0.536(0.160)$ & 0.724 & 0.835 & 0.911 & 20.6 & XOX \\
\hline & Anoxic & $\uparrow$ & Nonlinear & $0.560(0.146)$ & 0.591 & 0.335 & 0.736 & 19.8 & XXX \\
\hline \multirow[t]{2}{*}{ Fecosterol (\%) } & Oxic & $\downarrow$ & Nonlinear & $0.328(0.313)$ & 0.051 & 0.069 & 0.066 & 23.7 & XXX \\
\hline & Anoxic & $\downarrow$ & Nonlinear & $0.591(0.129)$ & 0.074 & 0.059 & 0.088 & 16.0 & XXX \\
\hline \multirow[t]{2}{*}{ Campesterol (\%) } & Oxic & $\downarrow$ & Nonlinear & $0.620(0.114)$ & 0.176 & 0.262 & 0.223 & 21.0 & XXX \\
\hline & Anoxic & $\downarrow$ & Nonlinear & $0.630(0.109)$ & 0.172 & 0.392 & 0.219 & 21.6 & XXX \\
\hline
\end{tabular}


Stigmasterol (\%)

Sitosterol (\%)

Sitostanol (\%)

Oxic
Anoxic
Oxic
Anoxic
Oxic
Anoxic

$\downarrow$
$\downarrow$
$\downarrow$
$\downarrow$
$\downarrow$
$\downarrow$

$\begin{array}{ll}\text { Nonlinear } & 0.495(0.185) \\ \text { Nonlinear } & 0.272(0.367) \\ \text { Nonlinear } & 0.427(0.232) \\ \text { Nonlinear } & 0.434(0.227) \\ \text { Nonlinear } & 0.638(0.105) \\ \text { Nonlinear } & 0.723(0.068)\end{array}$

a: The relationship is considered linear for $\mathrm{R}^{2}>0.8$ with a $p$-value $<0.01$.

0.056

0.328

0.069

$\mathrm{b}:$ The absolute value of the regression slope for the measured values.

c: The absolute value of the regression slope for the measured values divided by the average standard deviation of the measurement. A value of the $\mathrm{S}_{\mathrm{m}} / \mathrm{SD}$ superior to 1.0 was considered as an acceptable sensitivity in the source discrimination relative to the measurement uncertainty

d: The absolute value of the regression slope for the predicted values (e.g., data presented in Table S2).

e: The difference (\%) between the slope of the measured and predicted values. A difference of $<10 \%$ is considered an acceptable deviation.

$\mathrm{f}$ : The applicability is evaluated via the criteria based on $\mathrm{R}^{2}, \mathrm{~S}_{\mathrm{m}} / \mathrm{SD}$, and \% difference. O means the value of the standard respect the critical value while $\mathrm{X}$ the indices failed (e.g., Critical values for $\mathrm{R}^{2}$ and an associated $\mathrm{p}$-value of $\mathrm{R}^{2}, \mathrm{~S}_{\mathrm{m}} / \mathrm{SD}$ and \% difference are $>$ 0.8 and $<0.01,>0.5$, and $<10 \%$, respectively). 